University of Louisville

ThinkIR: The University of Louisville's Institutional Repository

Electronic Theses and Dissertations

$5-2012$

\title{
The Black-Scholes formula and volatility smile.
}

Brian Michael Butler 1969-

University of Louisville

Follow this and additional works at: https://ir.library.louisville.edu/etd

\section{Recommended Citation}

Butler, Brian Michael 1969-, "The Black-Scholes formula and volatility smile." (2012). Electronic Theses and Dissertations. Paper 188.

https://doi.org/10.18297/etd/188

This Master's Thesis is brought to you for free and open access by ThinkIR: The University of Louisville's Institutional Repository. It has been accepted for inclusion in Electronic Theses and Dissertations by an authorized administrator of ThinkIR: The University of Louisville's Institutional Repository. This title appears here courtesy of the author, who has retained all other copyrights. For more information, please contact thinkir@louisville.edu. 


\title{
THE BLACK-SCHOLES FORMULA AND VOLATILITY SMILE
}

\author{
By \\ Brian Michael Butler \\ B.A., Humboldt State University, 1993
}

\begin{abstract}
A Thesis
Submitted to the Faculty of the

College of Arts and Sciences of the University of Louisville in Partial Fulfillment of the Requirements for the Degree of
\end{abstract}

Master of Arts

Department of Mathematics

University of Louisville

Louisville, Kentucky

May 2012 
THE BLACK-SCHOLES FORMULA AND VOLATILITY SMILE

By

Brian Michael Butler

B.A, Humboldt State University, 1993

A Thesis Approved on

April 23, 2012

by the following Thesis Committee:

Ewa Kubicka, Thesis Director

Ryan Gill 


\section{DEDICATION}

This thesis is dedicated to my wife

Kelly Estep

whose loving support and encouragement

guided me onward in my education, and to our beautiful children, Aidan and Lily, who we hope to provide with the educational opportunities we received from our parents.

Also to my Great Aunt and Godmother, Hilda, who in her usual gentle and loving way encouraged me to persevere, and now it is done. 


\section{ACKNOWLEDGEMENTS}

The author would like to extend thanks to Professor Ewa Kubicka for suggesting this topic and providing the opportunity to explore it. Her knowledge and assistance were a great aid in the preparation of this work. 


\section{ABSTRACT \\ THE BLACK-SCHOLES FORMULA AND VOLATILITY SMILE}

Brian M. Butler

April 23, 2012

This paper investigates the development and applications of the Black-Scholes formula. This well-known formula is a continuous time model used primarily to price European style options. However in recent decades, observations in financial market data have brought into question some of the basic assumptions that the model relies on. Of particular interest is the prevalence of the volatility smile in asset option prices. This is a violation of one of the key assumptions under this model, and as a result alternatives to and modifications of Black-Scholes have been suggested, some continuous and some discrete. This paper researches one such modification, proposed by Derman and Kani (1994), in which observed market data is used to create a discrete time implied asset price tree that correctly reflects changing volatilities, risk-neutral probabilities, and observed option prices. The results are then used to price a less conventional derivative arrangement. 
TABLE OF CONTENTS

PAGE

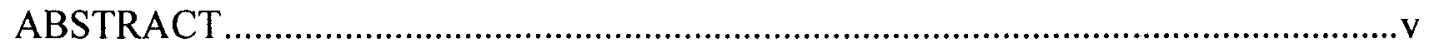

LIST OF TABLES .............................................................................................

LIST OF FIGURES ............................................................................................. vii

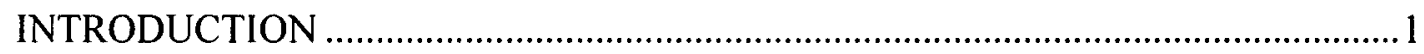

BACKGROUND ..............................................................................................

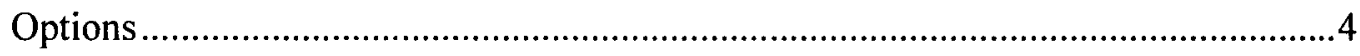

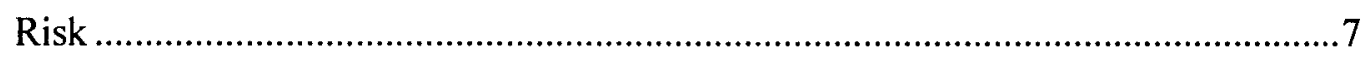

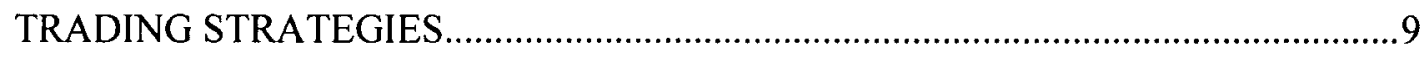

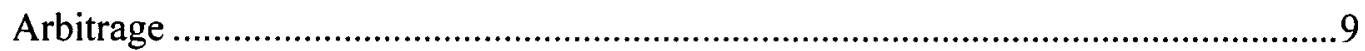

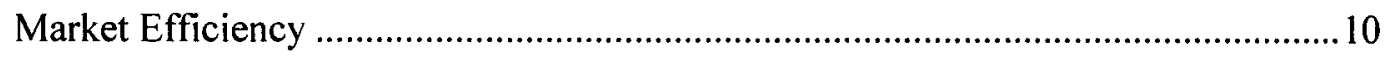

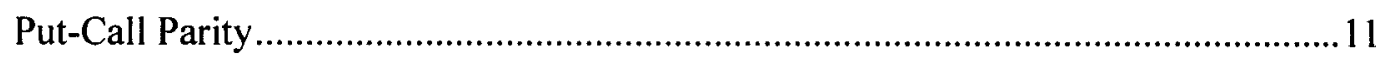

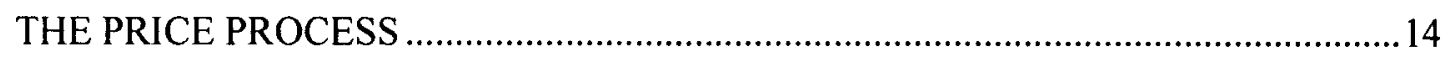

The Memoryless Property and Stochastic Processes ....................................................14

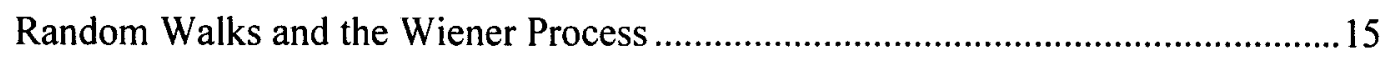

The Black-Scholes Pricing Formula ......................................................................18

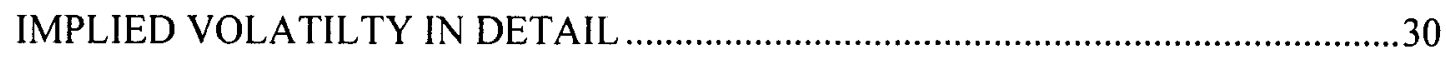

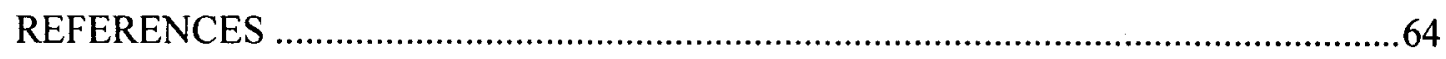

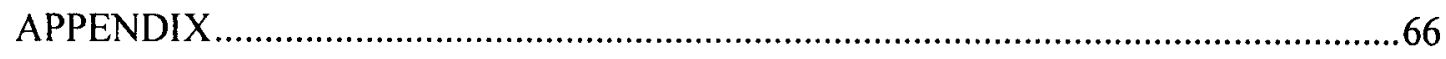

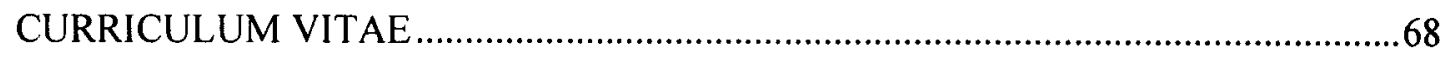




\section{LIST OF TABLES}

TABLE PAGE

TABLE 4.1 .... -

TABLE 4.2

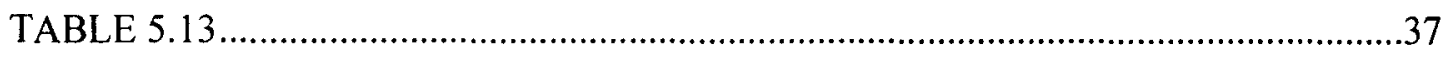




\section{LIST OF FIGURES}

$\begin{array}{ll}\text { FIGURE } & \text { PAGE }\end{array}$

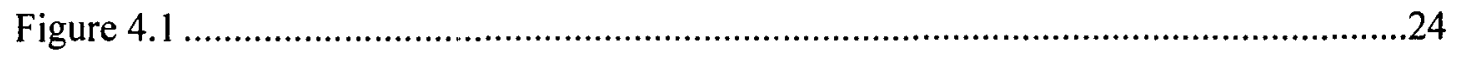

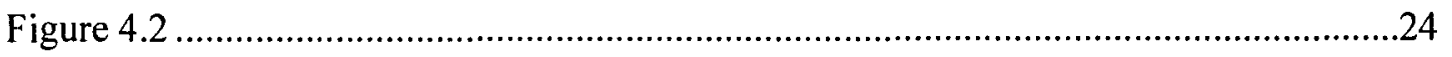

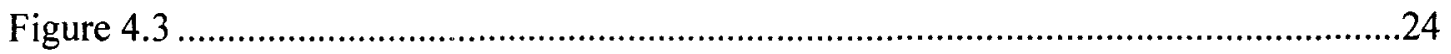

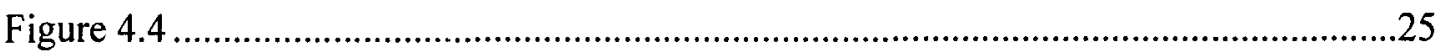

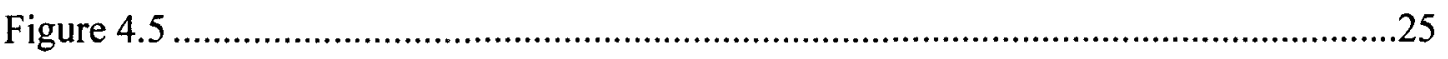

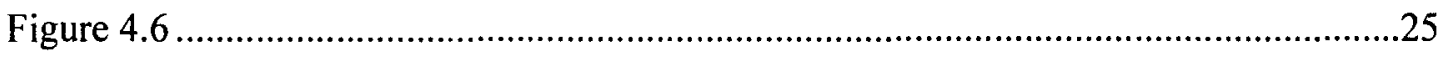

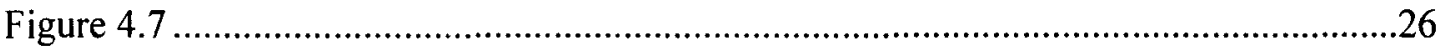

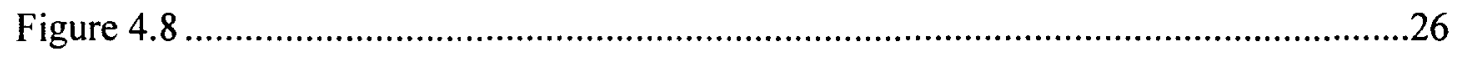

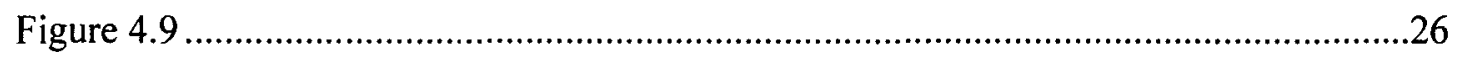

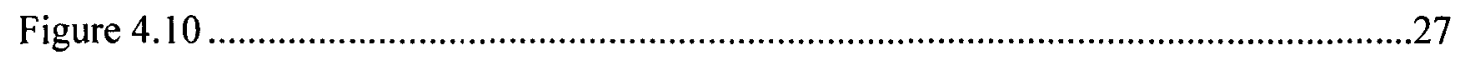

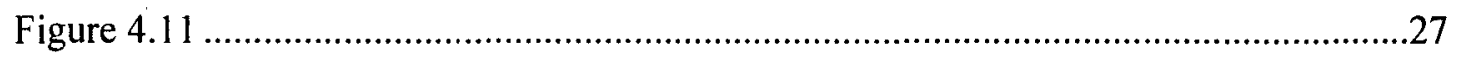

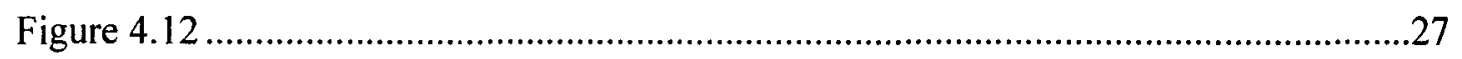

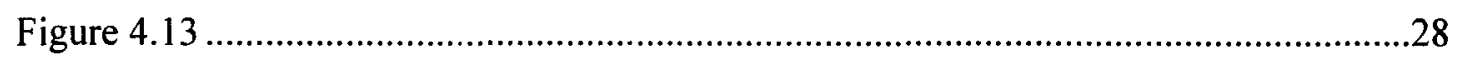

Figure 4.14

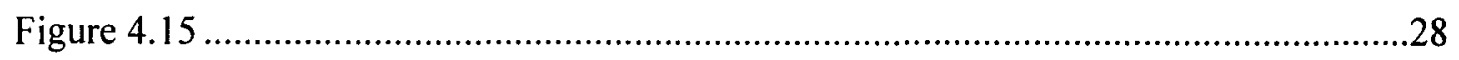

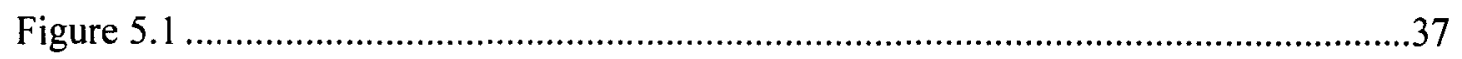

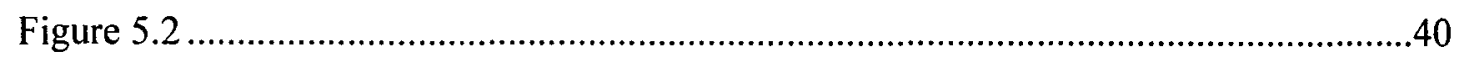

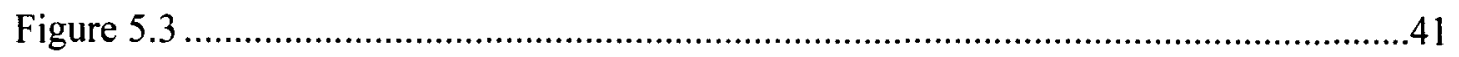

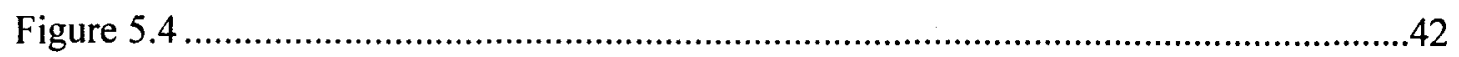




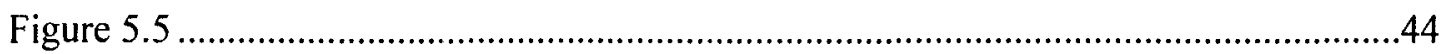

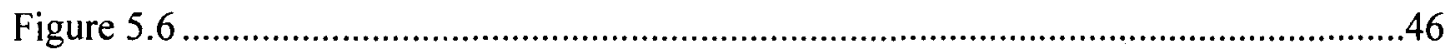

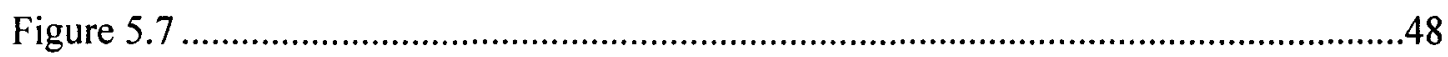

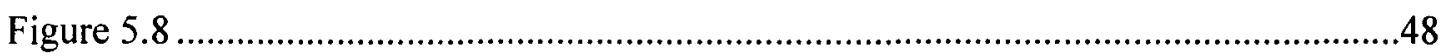

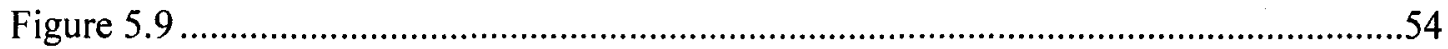

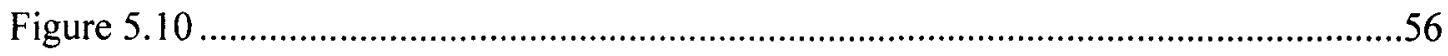

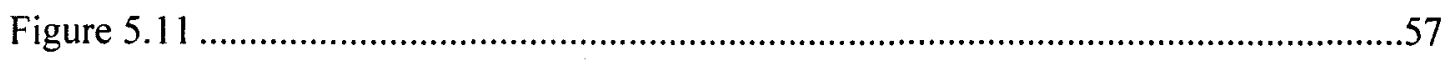

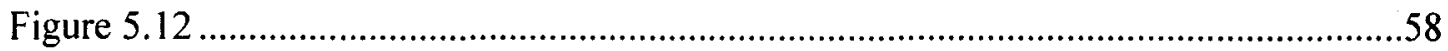

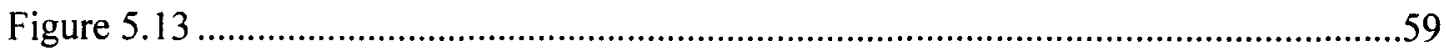

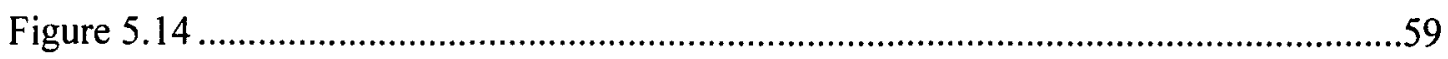

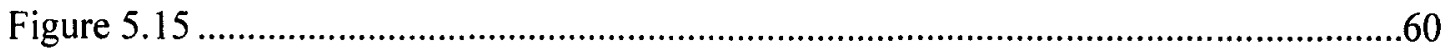




\section{CHAPTER 1}

\section{INTRODUCTION}

Although stock markets as we know them have existed in recognizable form for nearly five hundred years, it was not until surprisingly recently that some powerful mathematical tools were applied in the field of finance (see Bru, et al [6]). In fact, not until the middle of the twentieth century were probability models developed more fully and used in financial applications. Since that time a large amount of mathematical literature has been dedicated to financial applications, and in the last thirty years an entire body of work has emerged that aims to address some of the practical, real world problems encountered in pricing theory. In the early 1970s Black, Scholes, and Merton developed explicit models for use in the pricing of options. Although the celebrated Black-Scholes model has proven to be the foundation of modern financial engineering, it rests on a series of assumptions about the market and those who engage in market activity. As a result, the models can at times fail to capture some of the elements in the real-world financial markets. Researchers have systematically modified various parts of the model to address some of its shortfalls.

An area of particular interest is that of estimating volatility for the use in accurate pricing and proper application of various pricing models. Essential to the Black-Scholes formula and its variations are two parameter values - the drift rate and variance rate. Simply put the drift rate is the average increase per unit time of a stochastic process, and 
the variance rate is the average increase in the variance of the process per unit of time and is also the square of the volatility. Volatility can be estimated from a history of the stock price, where it is defined to be the standard deviation of the return provided by a stock over a time period, when returns are expressed using continuous compounding. However volatility can also be implied from observing option prices in the market.

Successfully incorporating the effects of risk into pricing theory not only yields a more accurate representation of the market, but also allows for more sophisticated financial engineering. Ultimately, the goal of financial engineering, as it pertains to risk, is to develop strategies that minimize the variation in returns. In the absence of a money machine, there should be no way to earn a riskless profit consistently from an efficiently functioning capital market. However, the market consistently exposes traders and investors to any of the types of risk just mentioned, and in the end the meaning of risk is the same - it is the uncertainty of the outcome. Naturally mathematical models serve to lend framework to the complex structure of the financial markets in an attempt to offer a more complete understanding of the underlying dynamics. When this is achieved, hedging strategies can be developed to counter the risk and make successful trading possible in the presence of exposure. Although the risk is not alleviated entirely, ideally speaking its impact can be minimized.

The purpose of this paper is to examine the mathematics of option pricing and the options market, to summarize some of the research and findings regarding volatility estimation, and to examine the effects of volatility on option pricing, and in particular the occurrence of volatility skew. Real stock market data will be used to estimate the needed values for option pricing, and a detailed example will be created to demonstrate the 
changing effects of volatility on prices. The paper will begin with general background information regarding options, risk, hedging, and pricing theory. More background will be presented as it is required during the development of the model. 


\section{CHAPTER 2}

\section{BACKGROUND}

\subsection{Options}

The word option has the same basic meaning when used in financial applications as it does when used in everyday language. It simply refers to an action that is not obligatory, but may or may not be undertaken according to the discretion of the participant. In finance this consists of the option to transfer an asset at some future date at a set price. One party has the right to take action, while the other party is required to adhere to the terms of the contract. The common types of options that will be discussed are known as call and put options, each of these can be further classified as either European or American.

Definition 2.1.1 A call option is a contract that gives the buyer the right to purchase a specific quantity of an asset at a specified price (called the exercise price or strike price) on or before a specified date (called the exercise date, expiration date, or maturity) as called for by the contract. For stocks the standard quantity is 100 shares.

Definition 2.1.2 A put option is a contract that gives the writer the right to sell a specific quantity of an asset at a specified price on or before a specified date as called for by the terms of the contract.

Definition 2.1.3 An option that can be exercised only on the exercise date is known as a European option. 
Definition 2.1.4 An option that can be exercised at any time prior to the exercise date is known as an American option.

As mentioned above, options are traded on organized exchanges, and it follows that there should be some solid financial reasoning for buying and selling options. Every option has a price, and in exchange for this price there is the chance of financial gain from exercising the option. It is only natural that a formula for valuing options would be developed that allows for consistent pricing and actually reflects elements of fairness while capturing the impacts of risk. But before addressing risk and valuation models, some elementary examples of options will be helpful. For completeness it is also worthwhile to note the following conventions of options exchanges:

i) options are typically traded one hundred at a time,

ii) strike prices are in increments of $\$ 2.50$ or $\$ 5.00$, and

iii) the expiration date in the US is the third Friday of the expiration month. In the options market, there are only two roles a trader can play - that of a purchaser of an option (known as the holder) and that of a seller of an option (known as the writer). These roles are also known as positions and a trader can have a different position for each transaction and can even be in more than one position at a time.

Definition 2.1.5 An investor who has purchased an option is said to have taken the long position.

Definition 2.1.6 An investor who has sold or written an option is said to have taken the short position.

Example 2.1 Suppose that a stock is currently selling at \$58, and a European call option is purchased on 100 shares for $\$ 3.75$ per share. The option has a maturity of six months 
and a strike price of $\$ 60$. If the stock is selling at $\$ 66$ six months from now and the option is exercised, then 100 shares can be purchased for $\$ 6000$ and sold for $\$ 6600$. Since the cost of the option was $\$ 375$, there is a gain of $(\$ 600-\$ 375)=\$ 225$ (in the absence of taxes and transaction costs). If instead the stock is selling for $\$ 63$ at maturity, it would still be worthwhile to exercise the option (still ignoring taxes and transaction costs). Although the difference $(\$ 6300-\$ 6000)=\$ 300$ is less than the cost of the option, namely $\$ 375$, and thus represents a loss of $\$ 75$, it is wise to exercise the option in order to partially offset the $\$ 375$ cost of option. The option would not be exercised if the share price in six months is below the exercise price, as this would only increase the loss. Overall there are only three possibilities for the outcome of exercising an option from the perspective of cash flow, namely a positive, zero, or negative cash flow can result. These outcomes are known as in-the-money, at-the-money, and out-of-the-money options, respectively.

The previous example gives some insight into the relationship between option prices and the prices of underlying assets. Intuitively it seems that in the case of a European call option, the potential for gain is dependent on how likely the stock price is to increase. Specifically, the likelihood for the stock price to increase or decrease is measured by volatility. What about the case of a European put option?

Example 2.2 Suppose that a particular stock is currently selling at $\$ 40$, and a European put option is bought to sell 100 shares at a strike price of $\$ 45$. The option has a maturity of six months and a cost of $\$ 2.75$ per share. If the stock is selling at $\$ 35$ six months from now and the option is exercised, then 100 shares can be purchased for $\$ 3500$ and sold for $\$ 4500$. Ignoring taxes and transaction costs, this yields a gain of $(\$ 4500-\$ 3500)=$ 
$\$ 1000$ less the option cost of $\$ 275$, or $\$ 725$ to the purchaser of the option.

Simply put, the purchaser of a call option looks to gain from stock price increases and the purchaser of a put option looks to benefit from stock price decreases. Once again, it can be seen that uncertainty in the market price of the stock lends itself to potential gain in options trading. More specifically holders of options can benefit from increased fluctuation if price changes work in their favor, but are not exposed to greater loss due to that uncertainty if price changes do not work in their favor. In the latter case they simply do not exercise the option. The remainder of this paper is primarily concerned with models for the value of European call options and will concentrate on that from this point.

Definition 2.2.1 A frictionless market is a theoretical market environment where no additional costs from the trade (movement) of securities exist.

Definition 2.2.2 A competitive market is a theoretical market environment where traders act as price takers without driving securities prices.

Theoretically financial markets would have no associated transaction costs, taxes, or trade restrictions that impact pricing and unlimited trading would not affect pricing. Although the frictionless market assumption has been the subject of many current extensions of classical theory, a way to incorporate trade size into pricing theory has been studied to a much lesser extent. It can be seen then that both Option Pricing with Liquidity Risk and Liquidity Risk and Arbitrage Pricing Theory address the very real situation in financial markets where the pricing process is affected by the supply and demand of a security and the size and timing of its trade. So far, researchers have used the concept of convenience yield to incorporate liquidity risk into pricing theory. 
Convenience yield simply stated is the gain associated with holding an asset instead of the derivative product. This indicates that there is a sense of risk associated with holding on to a low demand item (lack of marketability in a timely manner). This idea has been used in commodity market pricing, but for liquidity risk applications it fails to address a basic issue. Although it is successful in incorporating the facet of liquidity risk that has to do with inventory issues, and even exhibits conditions necessary to apply the usual arbitrage pricing theory, it does not "explicitly capture the impact of different trade sizes on the price. Consequently, there is no notion of bid/ask spread for the traded securities in this model structure. This is a significant omission because all markets experience price inelasticities (quantity impacts) and bid/ask spreads." [8] 


\section{CHAPTER 3}

\section{TRADING STRATEGIES}

\subsection{Arbitrage}

Without a consistent method for the assessment and incorporation of risk factors into derivative pricing, there exists the potential for traders to make a riskless profit. A simple example of how this works is illustrated by considering the price of common stock. If the situation existed where shares in the same company were trading in different exchanges for different prices (perhaps due to inconsistent valuation methods or exchange rate disparity), the efficient trader could buy low and sell high in a single stroke, thereby earning a free lunch. If the market did not drive prices of common stock according to the mechanisms of supply and demand, thereby allowing the price to reach equilibrium, this potential for a free lunch would continue.

Definition 3.1.1 The guarantee of a riskless profit resulting from a series of trades in the market is referred to as arbitrage.

Arbitrage typically results from disparities in price. The above example, though oversimplified, illustrates the role that price disparity plays in giving rise to arbitrage opportunity. Fortunately, mechanisms within capital markets work to ensure that arbitrage opportunities, should they arise, diminish as security prices adjust to meet the changing demand. Keep in mind that arbitrage refers to the guarantee of a riskless profit is essential to understanding the development of option pricing models, trading strategies, 
and hedging.

\subsection{Market Efficiency}

Definition 3.2.1 The Efficient Market Hypothesis states that all of the information relevant to the price of a security is reflected in the current price.

The idea of efficient capital markets ultimately results from the observation that security prices follow a random walk, which will be expanded on in Chapter 5. In general there are three forms of market efficiency considered by economists - weak-form, semistrong-form, and strong-form. The weak-form eliminates the use of historical information as a means for an investor to earn returns above the market average. Such information consists of past stock price changes and overall market activity, such as trading volume. The capital markets in the U.S. are generally thought to follow weakform efficiency. The semistrong-form eliminates the use of any publicly available information as a means for an investor to earn returns above the market average. When this type of information is made available, a semistrong-form efficient market will rapidly incorporate the information into the current security price. Clearly, a semistrongform efficient market implies that the market is also a weak-form efficient capital market. There is a great deal of research indicating that capital markets function at his level, for example see Fama, et al [13]. Finally is the level of efficiency that would eliminate the use of all public and private information as a means for an investor to earn returns above the market average. This strong-form efficiency of capital markets is not supported by evidence. Any of the insider trading scandals of the last hundred years serves as an example that private information can be used to earn excessive returns. However there is no guarantee that those engaged in such activity can do so consistently without the risk of 
legal repercussion.

\subsection{Put-Call Parity}

Allowing that the current stock prices incorporate all available public information and that historical information itself cannot be used to earn excessive returns, excluding insider trading, the ability for a trader to be guaranteed a riskless profit is the result of price disparity. In the case of European options of the same class (meaning they have the same strike price and maturity date), the prices of calls and puts are formulated in such a way as to, in a sense, bind them to each other and the market itself. If this is not the case then price disparity will arise and give way to arbitrage opportunity. The relationship between the price of a European call option, a European put option, and the market is known as the put-call parity.

Definition 3.3.1 The put-call parity is the relationship between two portfolios that protects against arbitrage opportunities in the market. One portfolio consists of a European call option with price $c$ and cash holdings equal to $K e^{-r T}$, and the other consists of a European put option with price $p$ and one share of stock with current price $S_{0}$, such that

$$
c+K e^{-r t}=p+S_{0}
$$

Here the term $K e^{-r T}$ is the present value of the strike price, discounted by the riskfree interest rate. The portfolio consisting of the purchased call option and the cash necessary to accumulate to the strike price at time $T$ must be equivalent to the purchased put option and the current value of a share of the stock. In other words, put-call parity states that these portfolios must have the same value now, or there will be a guaranteed advantage to owning one over the other. Consider the following example. 
Example 3.1 Suppose that stock $A$ is currently worth $\$ 36$ and that the six month riskfree interest rate is $8 \%$ per year. Further suppose that investor $B$ is given a quote for options on stock $A$ of $\$ 3.25$ for a European call and $\$ 2.75$ for a European put. Both options expire in six months and have a strike price of $\$ 35$. The value of portfolio $C$ consisting of the call and cash holdings is given by

$$
c+K e^{-r T}=3.25+35 e^{-0.08(6 / 12)}=\$ 36.87 \text {. }
$$

But the value of a portfolio $P$ consisting of the put and a share of the stock is given by

$$
p+S_{0}=2.75+36=\$ 38.75
$$

Investor $B$, knowing of this disparity, would see that portfolio $C$ is underpriced relative to portfolio $P$. The following series of transactions, known as a trading strategy (an arbitrage strategy in this case), would then be undertaken. Investor $B$ would buy the call option in portfolio A and sell (short) portfolio $P$ yielding an initial cash flow of

$$
-3.25+2.75+36=\$ 35.50
$$

This could then be invested at the risk-free rate for six months and accumulate to

$$
35.50 e^{0.08(6 / 12)}=\$ 36.95 \text {. }
$$

The call will be exercised if the stock price exceeds the strike price of $\$ 35$ and the put will be exercised if the price is below $\$ 35$. Exercising the call means buying one share at $\$ 35$ (below the market price), yielding a net profit of $\$ 36.95-\$ 35=\$ 1.95$. If the put is exercised investor $B$ will have to purchase one share for $\$ 35$ (above the market price) and a net profit of $\$ 36.95-\$ 35=\$ 1.95$ as well. Recalling that an option contract consists of 100 shares of the underlying stock, this would yield a guaranteed net profit of $\$ 195$ for investor $B$.

In the case where put-call parity does not hold, an arbitrage opportunity clearly 
occurs. But in efficiently functioning capital markets, it exists only briefly until traders exploit the disparity and supply and demand adjust the prices accordingly. This same parity can be also used to derive the price of a call given the price of a put and the current stock price, or to derive the price of a put given the call price and current stock price. This type of simplified analysis can indicate the presence of arbitrage as in the preceding example and similar examples can be used to illustrate the presence of arbitrage opportunities under different circumstances, such as on options involving dividendpaying stock. The end result is the same, namely that the unknowns that give rise to arbitrage strategy are the prices of the options. If a model is used to price call and put options in the absence of arbitrage opportunities, a variety of profit patterns arises depending on the trading strategy. None of these profits is considered riskless, however, and the problem arises of eliminating as much of the uncertainty as possible, a process known as hedging. 


\section{CHAPTER 4}

\section{THE PRICE PROCESS}

\subsection{The Memoryless Property and Stochastic Processes}

The widely accepted idea that capital markets function under weak-form efficiency is crucial to the mathematics of option valuation. Recall that weak-form efficiency indicates that above average returns cannot be earned by using historical information, such as average returns, as a mechanism for predicting future price activity. Mathematically speaking, this means that the underlying process that stock prices follow must be a memoryless process. This leads to the following discussion of stochastic processes, and eventually to the Black-Scholes Model.

Definition 4.1.1 A random variable $X$ is said to be without memory, or memoryless, if

$$
\operatorname{Pr}\{X \leq x+t \mid X>t\}=\operatorname{Pr}\{X \leq x\} \quad x, t>0
$$

The memoryless property is classically exhibited by the exponential distribution. In words it means that the likelihood of a particular future outcome depends only on the current state. The memoryless property is also known as the Markov property, and is of interest here as it relates to the memoryless property of a stochastic process.

Definition 4.1.2 A stochastic process (or random process) is a family of random variables $\{X(t), t \in T\}$ defined on a given probability space, indexed by the parameter $t$, where $t$ varies over an index set $T$.

For completeness it should be noted that a random variable is itself a function 
defined on a sample space $S$, so a stochastic process is actually a function of two arguments. The convention of denoting a stochastic process as only $X(t)$ will be adopted here. Further, note that the set of all possible values for the random variables is referred to as the state set or state space. Now in terms of a random process the memoryless property can be redefined.

Definition 4.1.3 A stochastic process $\{X(t), t \in T\}$ is said to be Markov process if $\operatorname{Pr}\left\{X\left(t_{n+1}\right) \leq x_{n+1} \mid X\left(t_{n}\right)=x_{n}, X\left(t_{n-1}\right)=x_{n-1}, \ldots, X\left(t_{1}\right)=x_{1}\right\}=\operatorname{Pr}\left\{X\left(t_{n+1}\right) \leq x_{n+1} \mid X\left(t_{n}\right)=x_{n}\right\}$, whenever $t_{1}<t_{2}<\ldots<t_{\mathrm{n}}<t_{\mathrm{n}+1}$. A discrete-state Markov process is called a Markov chain.

The relationship illustrated by the above definition is known as the Markov property, or memoryless property. It indicates that the future state of such a process is not determined by the past states or past history of the process, but only by the current state. More specifically, the Markov property shows no dependence on the manner in which the current state arose, but only on the current state itself. The thought here is that all of the previous information, prior to the current state of the process, is inherently integrated into the current state, and only this current state is a factor. In terms of stock prices and weakform efficiency, it is clear that the underlying price process of stocks could be described by a Markov process.

\subsection{Random Walks and the Wiener Process}

Early investigation into stock prices, such as that conducted by Kendall [18], was done in part to expose cyclical patterns in the markets. Such research only reinforced even earlier work, such as that done by Bachelier, suggesting that stock price movements were actually random processes. In fact, Bachelier's work had largely slipped out of 
view, although his development of the mathematics of random processes predated even Einstein, whose work on colliding gas molecules relied heavily on a particular type of random process known as Brownian motion. Brownian motion is used generically to describe the motion of a collection of particles that are subject to a random walk. A random walk in turn is typically described as a discrete Markov process composed of a number of independent steps. Whereas the Markov property ensures that only the current state is relevant to future stock prices, an extended period of observation time in the future has some effect on the amount of uncertainty in the value in the future. So these rates are proportional to the length of the interval (or index set) $T$.

Definition 4.2.1 The drift rate is defined to be the average increase per unit time of a stochastic process.

Definition 4.2.2 The variance rate is defined to be the average increase in the variance of the process per unit of time.

Definition 4.2.3 A variable $Z$ is said to follow a particular type of Markov process, known as a Wiener process if the following properties are satisfied:

Property 1. The change $\Delta z$ during a small period of time $t$ is $\Delta z=\varepsilon \sqrt{\Delta t}$, where $\varepsilon$ is a random drawing from the standard normal distribution $M(0,1)$.

Property 2. The values for $\Delta z_{1}$ and $\Delta z_{2}$ that correspond to any two nonoverlapping short intervals of time, $\Delta t_{1}$ and $\Delta t_{2}$, are independent.

It follows immediately then that $\Delta z$ follows a normal distribution with mean 0 and variance $\Delta t$ since

$$
\begin{gathered}
\mathrm{E}[\Delta \mathrm{z}]=\mathrm{E}[\varepsilon \sqrt{\Delta t}]=(\sqrt{\Delta t}) \mathrm{E}[\varepsilon]=0, \text { and } \\
\operatorname{Var}[\Delta z]=\operatorname{Var}[\varepsilon \sqrt{\Delta t}]=(\sqrt{\Delta t})^{2} \operatorname{Var}[\varepsilon]=\Delta t
\end{gathered}
$$


If the limit as $\Delta t \rightarrow 0$ is considered, then a generalized Wiener process for a variable $X$ can be defined in terms of a Wiener process $d Z$, as $d X=a d t+b d Z$, where $a$ and $b$ are constants representing incremental drift and variance rates respectively. Again considering the discrete version over a small time interval $\Delta t$, this becomes

$$
\Delta x=a \Delta t+b \varepsilon \sqrt{\Delta t}
$$

It then follows that

$$
\begin{aligned}
& \mathrm{E}[\Delta X]=\mathrm{E}[a \Delta t+b \varepsilon \sqrt{\Delta t}]=\mathrm{E}[a \Delta t]+\mathrm{E}[b \varepsilon \sqrt{\Delta t}]=a \Delta t+b \mathrm{E}[\Delta z]=a \Delta t \\
& \operatorname{Var}[\Delta X]=\operatorname{Var}[a \Delta t+b \quad \varepsilon \sqrt{\Delta t}]=0+b^{2} \operatorname{Var}[\Delta z]=b^{2} \Delta t
\end{aligned}
$$

If a longer interval of time is considered, say from 0 to $T$, it turns out that the mean increase in $x$ over the interval (drift rate) is $a T$ and the variance of change over the interval (variance rate) is $b^{2} T$. This suggests that although a generalized Wiener process may seem an ideal model for stock price changes, it fails in one important respect. Recalling that the expected return and the stock price are independent, it is wrong to assume a constant drift rate over an interval. An appropriate adjustment gives way to a working model that uses geometric Brownian motion instead, where the expected return (drift divided by price) is constant. The discrete-time version of geometric Brownian motion for the change $\Delta S$ in stock price $S$, in a short interval of time $\Delta t$ is

$$
\Delta S=\mu S \Delta t+\sigma S \varepsilon \sqrt{\Delta t}
$$

The Black-Scholes differential equation is derived from this relationship, and is not dependent on the expected return. Solutions to the Black-Scholes differential equation yield the equations used to price various options, including the European call options with which this paper is concerned. Since expected returns have been removed from the option pricing formula, all investors expect to obtain the same price for a particular 
option. As will be shown in the next section, the Black-Sholes model makes a number of assumptions that allow for this fair valuation to happen.

\subsection{The Black-Scholes Pricing Formula}

A method such as the Binomial Model (see Hull [14] or Shreve [28]) to price stock options introduces some properties that are desirable to retain in a model such as the Black-Scholes model. Namely, a riskless portfolio can be created and, in the absence of arbitrage, the return is the risk-free interest rate.

Definition 4.3.1 A portfolio is said to be a riskless portfolio if it consists of holdings of a stock and options on that stock such that there is no uncertainty about the portfolio value at expiration.

In a Black-Scholes economy, a position in the option and stock portfolio is riskless for only a very brief time. The following example illustrates an important result of this. Example 4.1 Suppose that the price movements of a particular stock, $S$, and a European call option, $c$, change according to the equation $\Delta c=0.3 \Delta S$, at some particular time. At that time, a riskless portfolio would consist of purchasing 0.3 shares of the stock and selling one call option.

But as time goes on the relationship between $\Delta c$ and $\Delta S$ will vary. As a result, the portfolio must be rebalanced as frequently as the relationship changes. This is essential to the Black-Scholes pricing formulas, and introduces the problem of liquidity risk. Since rebalancing consists of making transactions, and transactions not only incur costs directly, but can also impact prices (according to supply and demand effects) thereby creating costs indirectly, the frequency of rebalancing has an obvious cost. Very frequent rebalancing would certainly get expensive quickly. And the continuous rebalancing 
necessary for the perfect hedge in the Black-Scholes model is impossibly expensive in the face of transaction costs. As for the derivation of the Black-Scholes Model itself, several assumptions were made:

1. The stock price follows the process $\Delta S=\mu S \Delta t+\sigma S \Delta z$, with $\mu$ and $\sigma$ constant.

2. Short selling with full use of proceeds is allowed.

3. There are no transaction costs or taxes (frictionless).

4. The stock pays no dividend during the option life.

5. There are no riskless arbitrage opportunities.

6. Trading is continuous.

7. The risk-free rate, $r$, is constant and is the same for options of all maturities. Under these assumptions, the Black-Scholes differential equation [4] was derived, a solution to which yields the following equation.

Equation 4.3.1 The Black-Scholes formula for the price of a European call option at time zero, on a non-dividend-paying stock is given by

$$
\begin{array}{cc}
c=S_{0} N\left(d_{1}\right)-X e^{-r T} N\left(d_{2}\right), & \text { where } \\
d_{1}=\left[\ln \left(S_{0} / X\right)+\left(r+\sigma^{2} / 2\right) T\right] /[\sigma \sqrt{T}] \\
d_{2}=d_{1}-\sigma \sqrt{T}, & \text { and }
\end{array}
$$

$N(x)$ is the cumulative probability distribution function of the standard normal variable, $S_{0}$ is the stock price at time $0, X$ is the strike price, $\sigma$ is the volatility, and $T$ is the time to maturity of the option. There are some boundary conditions inherent in the model which are discussed in some detail in Hull [14], but will not be discussed here. Additional definitions will add to the overall understanding of the model and lead nicely into the topic of volatility. 


\section{Definition 4.3.2 The cumulative probability distribution function of the standard}

normal variable, $N(x)$, is the probability that a number drawn from a standard normal distribution (a normal distribution with mean 0 and standard deviation 1) will be less than $x$. In general a standard normal variable, $Z$, is calculated according to the following transformation $Z=(X-\mu) / \sigma$ and the normal density function is defined as follows

$$
P(a \leq X \leq b)=\int_{a}^{b} \frac{1}{\sigma \sqrt{2 \pi}} e^{-(x-\mu)^{2} /\left(2 \sigma^{2}\right)} d x
$$

Definition 4.3.3 Historical volatility is the standard deviation of the return provided by a stock over a one-year period, when returns are expressed using continuous compounding.

In general volatility can be thought of as a measure of the uncertainty of realized returns on an asset. The calculation of historical volatility is demonstrated below. It can be seen that measuring volatility based on historical stock prices will yield a constant value for the time period considered and does not explicitly take options trading or derivatives pricing into account when computing. The Black-Scholes formula assumes constant volatility, but by observing the behavior of option prices in the market a different picture emerges. If all values save volatility are taken from observed market data and input into the Black-Scholes formula, then the formula can be solved for the unknown value, namely volatility. This is known as implied volatility and will be covered in detail in Chapter 5.

Definition 4.3.4 Implied volatility is the value calculated using observed option proces in the market.

Consider the market data on ten stocks (see Table 4.1) that were chosen such that none had experienced a stock split over the period from 1997 to 2003 . The closing price of each stock on the last trading day of the calendar year was used for the price for that 
period. Ignoring dividends and letting the interest rate be zero without loss of generality, these prices were used to calculate estimates of the expected return and volatility for each company, according to the method illustrated in Hull [15]. The method results from a number of assumptions mentioned previously regarding the distribution of stock prices. It is also assumed that percentage changes in stock price over a small interval of time follow a normal distribution with mean $\mu$ and standard deviation $\sigma$, or

$$
\frac{d S}{S} \sim N(\mu d t, \sigma \sqrt{d t}) .
$$

Recall that according to the Black-Scholes model, stock prices follow a random walk.

\begin{tabular}{|l|l|l|l|}
\hline Company & mu & sigma & $\mathbf{S}_{0}$ \\
\hline Cameco Cp CCJ & 0.224271 & 0.497187 & $\$ 58.14$ \\
\hline Cummins Engines CMI & 0.038796 & 0.403161 & $\$ 59.23$ \\
\hline CNS Inc CNXS & 0.228694 & 0.476473 & $\$ 10.18$ \\
\hline Cross Timber Royalty Trust CRT & 0.159209 & 0.381147 & $\$ 29.30$ \\
\hline Eagle Materials EXP & 0.165616 & 0.304197 & $\$ 70.40$ \\
\hline Idexx Laboratories IDXX & 0.251474 & 0.360068 & $\$ 58.80$ \\
\hline Navigators Group Inc NAVG & 0.136076 & 0.341421 & $\$ 28.71$ \\
\hline Neurocrine Biosciences NBIX & 0.574124 & 0.520898 & $\$ 50.01$ \\
\hline Pepsi Co & 0.058288 & 0.18568 & $\$ 53.18$ \\
\hline Quality Systems Inc QSII & 0.500508 & 0.528764 & $\$ 47.02$ \\
\hline Everest Re Group Ltd RE & 0.337693 & 0.6048 & $\$ 79.06$ \\
\hline
\end{tabular}

Table 4.1 Estimates for all ten sampled companies and the stock price of each on July 8, 2004.

This assumption is equivalent to saying that future stock prices follow a lognormal distribution. It is common to see the lognormal distribution in financial and actuarial applications because it is restricted to positive values and is positively skewed. A variable $Y$ is said to be lognormal when $\ln Y$ follows a normal distribution. In the case of the Black-Scholes model $\ln S_{T}$ follows a normal distribution according to

$$
\ln S_{T} \sim N\left[\ln S_{0}+\left(\mu-\frac{\sigma^{2}}{2}\right) T, \sigma \sqrt{T}\right], \text { or }
$$




$$
\ln \frac{S_{T}}{S_{0}} \sim N\left[\left(\mu-\frac{\sigma^{2}}{2}\right) T, \sigma \sqrt{T}\right],
$$

where $N(m, n)$ is the cumulative normal distribution with mean $m$ and standard deviation $n$, and $S_{T}$ is the stock price at a future time $T$. When $T=1, \ln \frac{S_{T}}{S_{0}}$ is the continuously compounded return over one year.

Definition 4.3.4 The ratio of an asset price in a given period of time to its price in the preceding period is known as the price relative.

Since the interval of observation used here is one year, an estimate for the expected return on a stock can be found by averaging the price relatives over the period of observation. The volatility can then be estimated as the standard deviation of the natural $\log$ of the price relatives over the period of observation. Table 4.2 shows the specific calculation for one of the ten sampled companies, CCJ.

\begin{tabular}{|l||l|l|l|l|l|}
\hline Cameco Cp CCJ & Year & $\mathbf{i}$ & Close & mu & sigma \\
\hline & 2003 & 19 & $\$ 57.60$ & 1.40501 & 0.877554 \\
\hline & 2002 & 18 & $\$ 23.95$ & -0.03271 & -0.03326 \\
\hline & 2001 & 17 & $\$ 24.76$ & 0.414857 & 0.347029 \\
\hline & 2000 & 16 & $\$ 17.50$ & 0.157025 & 0.145852 \\
\hline & 1999 & 15 & $\$ 15.13$ & -0.15088 & -0.16355 \\
\hline & 1998 & 14 & $\$ 17.81$ & -0.44767 & -0.59362 \\
\hline & 1997 & 13 & $\$ 32.25$ & & \\
\hline & & & & 0.224271 & \\
\hline & & & & & 0.497187 \\
\hline volatilty estimate & & & & \\
\hline
\end{tabular}

Table 4.2 Estimates for the expected return and volatility of CCJ stock.

We now have a model for pricing a European call option that captures the essence of stock price movements as a memoryless random process. This process consists of a number of independent movements, each increment of which is drawn from a normal distribution. Furthermore, all of the parameters necessary for applying Equation 4.3.1 can be obtained from available data. An important element to first explore is the relationship 
between these parameters and the option price generated by the Black-Scholes formula. Although the relationship between volatility and option price is the most useful in the present work, the effects of time-to-maturity, strike price, and current asset price on option price will also be investigated.

In the following figures, graphic representations of these relationships are presented. Each graph was generated using DerivaGem 1.51 and in each case a risk free interest rate of $3 \%$ was used. Figure 4.1, Figure 4.2, and Figure 4.3 illustrate the effect that current asset price $\left(S_{0}\right)$ has on the option price for securities with a volatility of $20 \%$, $40 \%$, and $60 \%$ respectively. (In general so-called old economy securities have a volatility in the range between $20 \%$ and $40 \%$, whereas new economy securities have a volatility between $40 \%$ and $60 \%$, Hull [14]). The effect that volatility has on option price for securities with various prices is represented in Figure $4.4-4.9$. And finally the effect that strike price has on option price for a number of securities with various current prices and volatilities is represented in Figure $4.10-4.15$. The relationship between option price and time-to-maturity is not as certain however.

These graphs are only representative of the general trend occurring when certain variables are allowed to change. More specifically, the value of a European call option increases as the price of the underlying stock increases, ceter paribus (all other values unchanged). In Figures $4.4-4.9$ it can be seen that as the volatility on a given security increases the option value also increases, ceter paribus. So the greater the likelihood of large price changes, the greater the potential payoff and, therefore, the more valuable the option. In Figures $4.10-4.15$ it can be seen that as the strike price on an option increases 

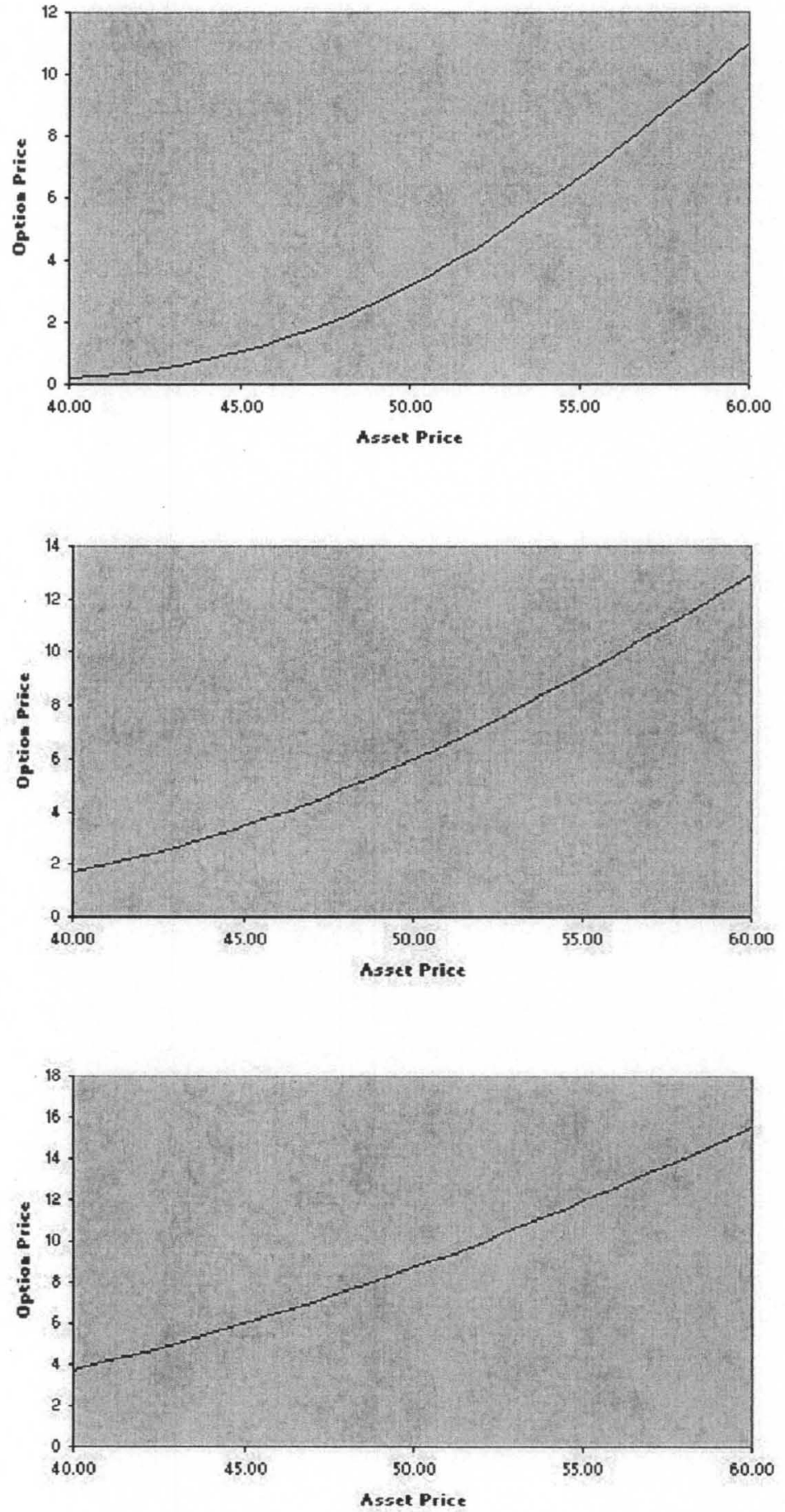

Figure 4.1 Graph of option price as a function of current asset price, with a volatility of $20 \%$. Created using DerivaGem 1.51.

Figure 4.2 Graph of option price as a function of current asset price, with a volatility of $40 \%$. Created using DerivaGem 1.51.

Figure 4.3 Graph of option price as a function of current asset price, with a volatility of $60 \%$. Created using DerivaGem 1.51. 

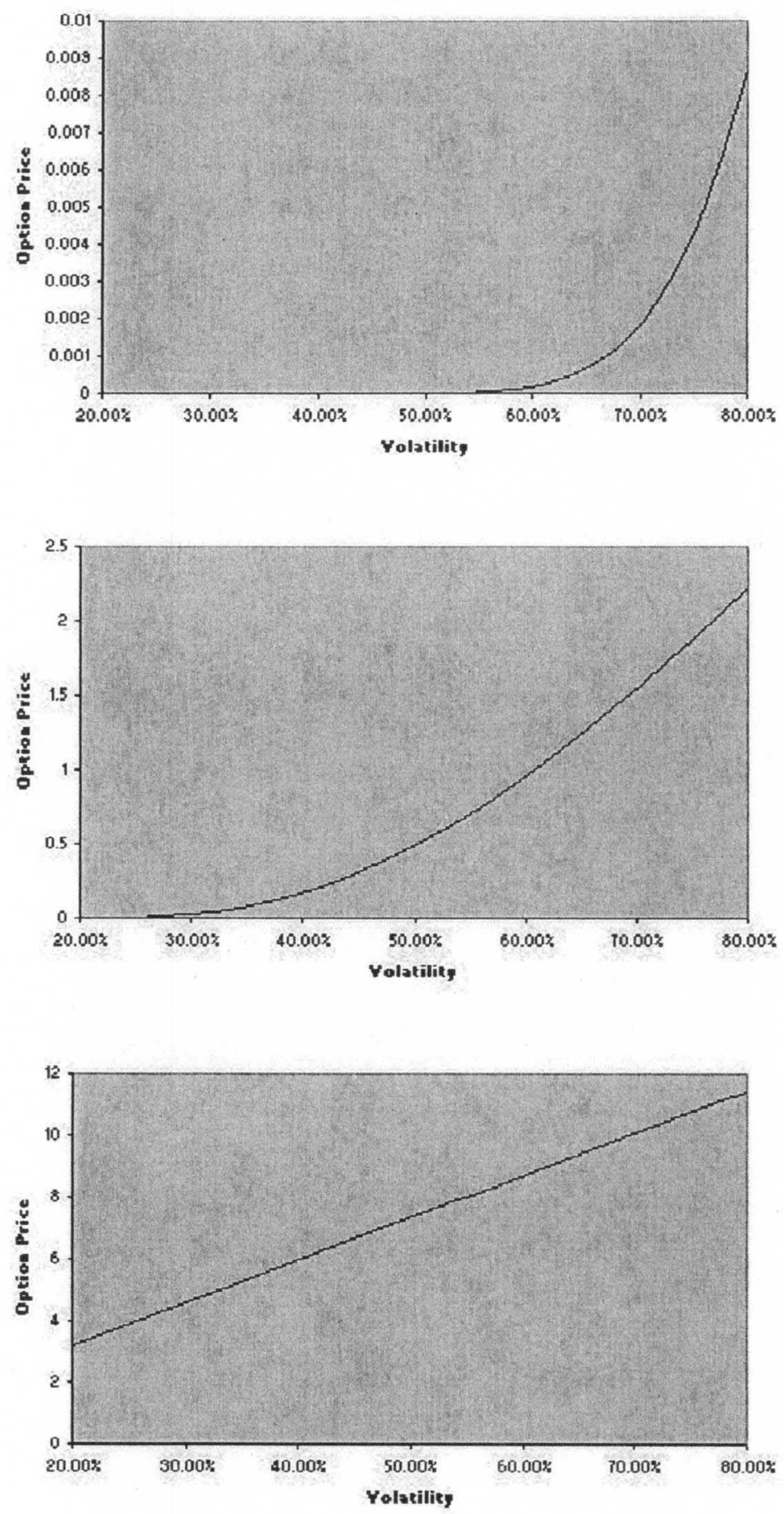

Figure 4.4 Graph of option price as a function of volatility, with a current asset price, $S_{0}$, of $\$ 10$.

Figure 4.5 Graph of option price as a function of volatility, with a current asset price, $S_{0}$, of $\$ 30$.

Figure 4.6 Graph of option price as a function of volatility, with a current asset price, $S_{0}$, of $\$ 50$. 

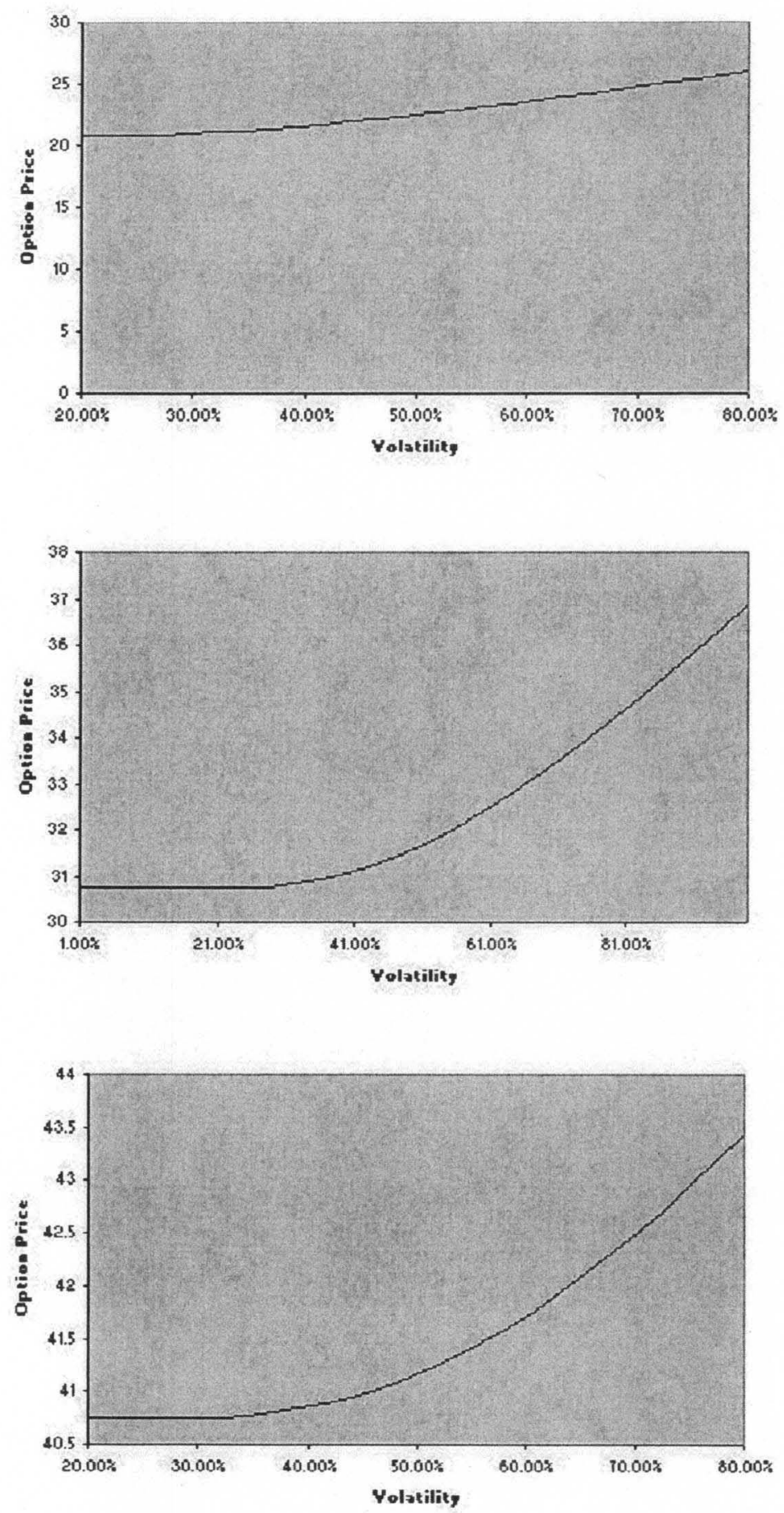

Figure 4.7 Graph of option price as a function of volatility, with a current asset price, $S_{0}$, of $\$ 70$.

Figure 4.8 Graph of option price as a function of volatility, with a current asset price, $S_{0}$, of $\$ 80$.

Figure 4.9 Graph of option price as a function of volatility, with a current asset price, $S_{0}$, of $\$ 90$. 

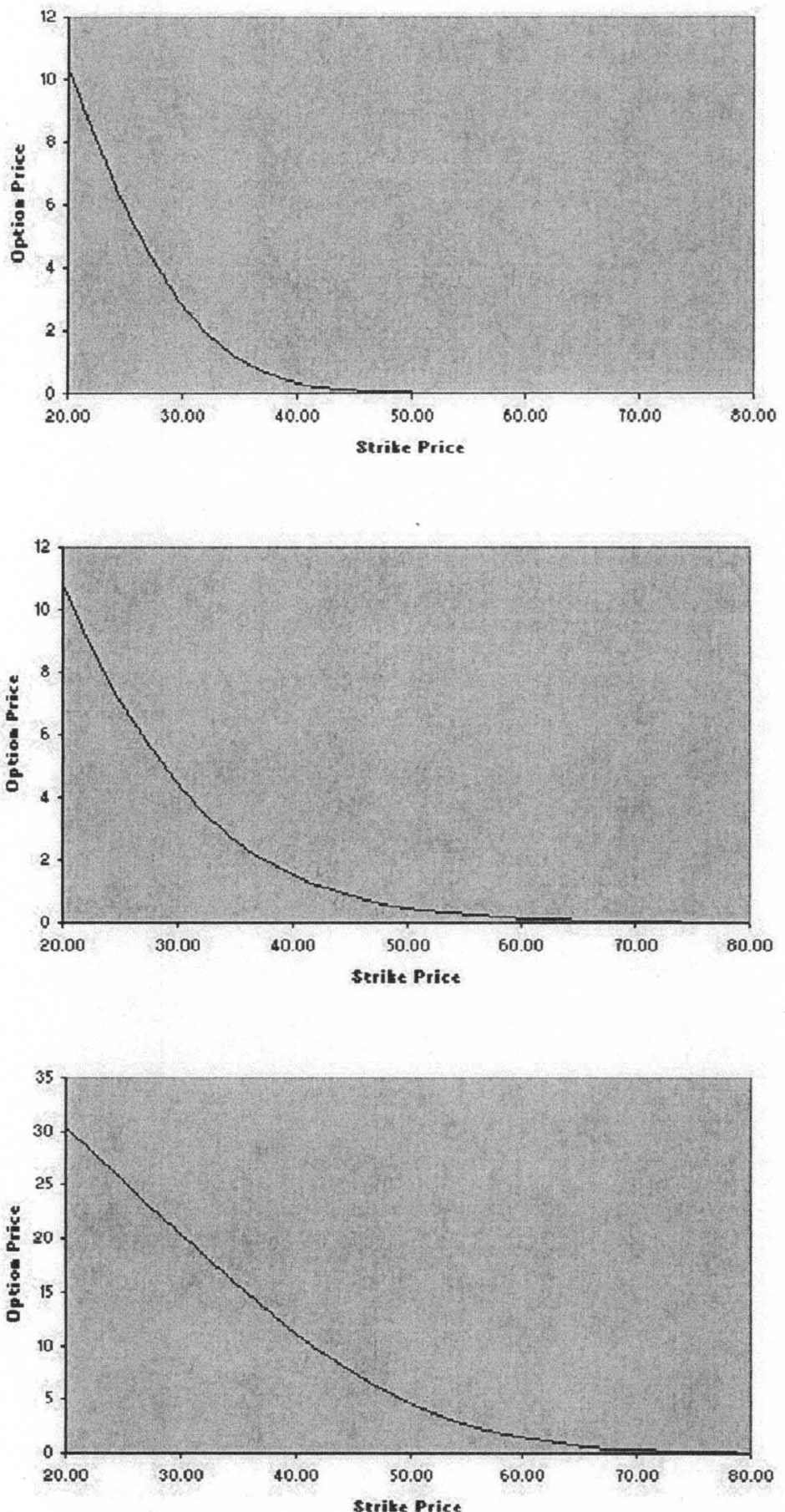

Figure 4.10 Graph of option price as a function of strike price, $K$, with an asset price, $S_{0}$, of $\$ 30$ and volatility of $30 \%$.

Figure 4.11 Graph of option price as a function of strike price, $K$, with an asset price, $S_{0}$, of $\$ 30$ and volatility of $50 \%$.

Figure 4.12 Graph of option price as a function of strike price, $K$, with an asset price, $S_{0}$, of $\$ 50$ and volatility of $30 \%$. 


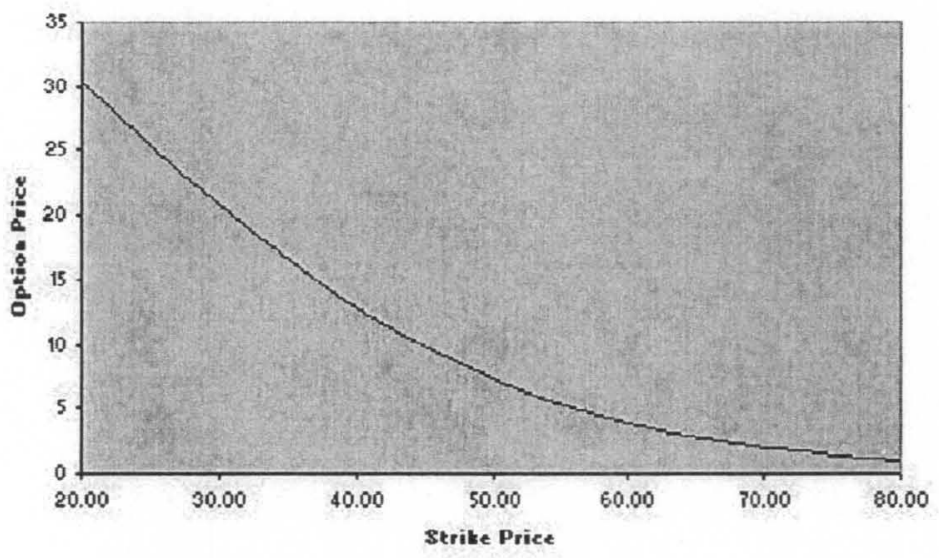

Figure 4.13 Graph of option price as a function of strike price, $K$, with an asset price, $S_{0}$, of $\$ 50$ and volatility of $50 \%$.

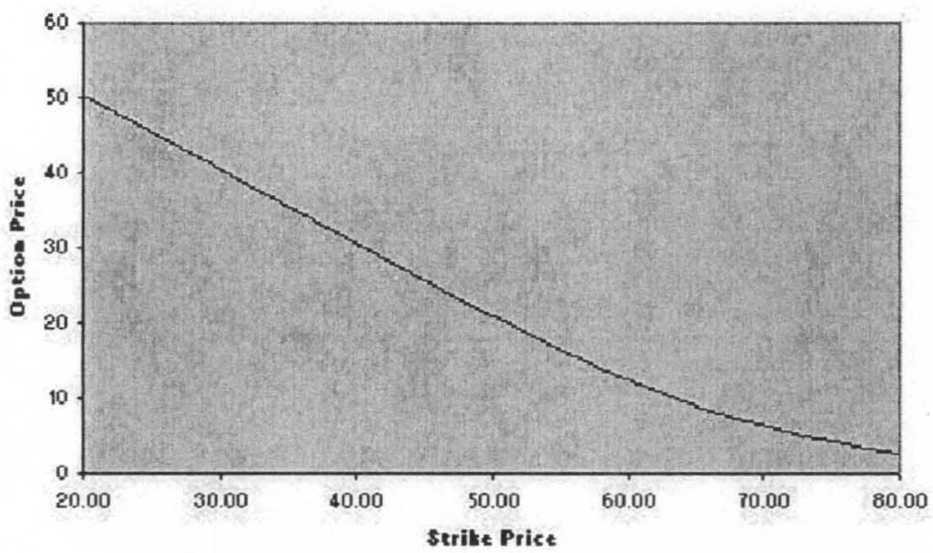

Figure 4.14 Graph of option price as a function of strike price, $K$, with an asset price, $S_{0}$, of $\$ 70$ and volatility of $30 \%$.

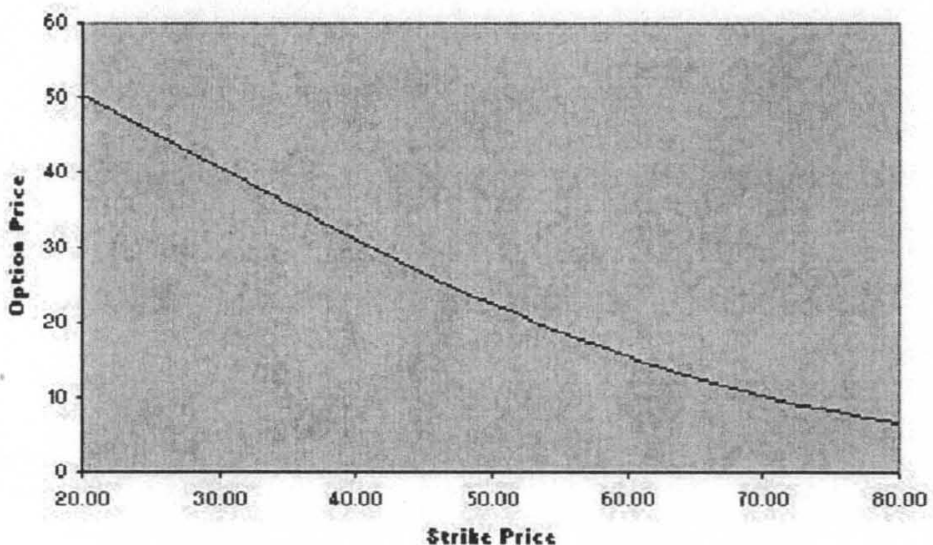

Figure 4.15 Graph of option price as a function of strike price, $K$, with an asset price, $S_{0}$, of $\$ 70$ and volatility of $50 \%$.

the value of the option decreases, ceter paribus. For a set stock price, $\$ 30$ for example as in Figure 4.11 and Figure 4.12, an increase in volatility from $30 \%$ to $50 \%$ results in less curvature. So when the likelihood of larger changes in price is greater, the option price 
seems to decrease more gradually.

The general effects are of interest here and are as follows: an increase in stock price causes an increase in option price, an increase in volatility causes an increase in option price, and an increase in strike price causes a decrease in option price. In the current work it is assumed without loss of generality that the risk-free interest rate is zero, that the stocks are all non-dividend paying, and that all call options have a six-month maturity. For completeness it should be noted then that as the risk-free rate increases the value of the option increases. However as the time to expiration increases, the general effect is uncertain. Dividends present a slightly more complicated situation in that dividend payment lowers the stock price at the time the trade takes place, known as the ex-dividend date. Also the value of the option is affected based on the anticipated dividend, and in the case of a call option, its value is negatively affected by an expected dividend. 


\section{CHAPTER 5}

\section{IMPLIED VOLATILTY IN DETAIL}

As discussed in Chapter 4, the historical volatility that can be calculated from observed stock prices is constant for the period considered. As a practical application, one would observe a six month history in order to calculate the historical volatility for use in pricing a six-month option on the same underlying asset. However by observing the prices of six-month options on a stock for different strike prices on a given day, the implied volatility can be calculated using an option pricing model such as the BlackScholes formula. Recall that there are a number of assumptions at the heart of the BlackScholes formula, some of which are not a strict requirement under the framework. In fact some assumptions have been relaxed in many cases, or an alternative approach has been found that allows the assumption to be modified. A good example is the assumption that the stock pays no dividend during the option life. As previously mentioned this is known as an ex-dividend date, and alternative models exist for using the Black-Scholes framework to price options when there is a dividend payment during the life of the option. However a more crucial assumption lies at the base of the Black-Scholes framework that has sparked a lot of curiosity and research, namely the assumption that the volatility of the underlying equity is constant.

The primary assumption of the Black-Scholes formula is that stock prices follow the process $\Delta S=\mu S \Delta t+\sigma S \Delta z$, with $\mu$ and $\sigma$ constant. Dividing both sides by the stock 
price $S$ leads back to the previous discussion regarding the lognormality of stock prices. Note that the assumption made is not simply that the volatility on a given equity is constant, but that it is constant across different strike prices. Therefore by collecting market data on call options for a given stock for a variety of strike prices, with the same time to maturity, the implied volatility for the underlying stock can be calculated using the Black-Scholes formula (Formula 4.3.1 above). If the underlying assumption of BlackScholes framework holds then the obvious, expected result would be that the implied volatility is constant for that stock.

However the implied volatility is not constant and for options on stocks it actually decreases as the strike price increases. This general description holds true for both put and call options when you consider the "moneyness" of the option, although the focus here will be on European call options. Recall that an at-the-money option indicates that if the option is exercised immediately, the holder of the option would break even - the resulting cash flow is therefore at the money. Similarly when an option is referred to as in-the-money, if the holder could exercise right away the resulting cash flow would be positive for the holder. And again similarly when an option is referred to as out-of-themoney, if the holder could exercise right away the resulting cash flow would be negative for the holder. Now the general description referred to above states that implied volatility increases as the strike price decreases. As a stock price decreases a call option would be in-the-money, while a put option would be out-of-the-money as illustrated by the following example.

Example 5.1 Suppose that a stock is currently selling at $\$ 55$, and a European call option is purchased on 100 shares for $\$ 3.75$ each. The option has a maturity of six months and a 
strike price of $\$ 50$. If the holder of the option could exercise it at that moment, the resulting cash flow would be as follows. The holder would receive 100 shares for $\$ 5,000$ after initially spending $\$ 375$ on the options, for a total expenditure of $\$ 5,375$. However, the 100 newly acquired shares of stock are worth $\$ 55$ per share on the market for a total of $\$ 5,500$ resulting in a positive cash flow of $\$ 125$ (in the absence of taxes and transaction costs). Suppose instead that the 100 options under consideration were for a European put selling for $\$ 1.90$ each. Then holder would have to sell 100 shares for $\$ 50$ each when they are worth $\$ 55$ each on the open market. This would result in a negative cash flow of $\$ 190$ for the options themselves and a market loss of $\$ 500$ for a negative cash flow of $\$ 690$ for the holder of the put.

Table 5.1 shows the implied volatility calculated for six-month European call options on shares of Cameco Cp stock (CCJ) expiring in March 2012. Option prices were collected from the CBOE website, and the implied volatility was calculated using the goal seek feature in Microsoft Excel. CCJ paid no dividends during the period of the option life. The at-the-money option is highlighted in the table and represents the option associated with a strike price of $\$ 25$, that being the closest to the stock price of $\$ 25.20$ at the time the options were written. The risk-free rate, $r$, was assumed to be $3 \%$ without the loss of generality. As you can observe from the data in Table 5.1, when $K=\$ 7$ the implied volatility is at its highest and as $K$ increases and approaches the at-the-money option the volatility decreases.

The phenomenon of non-constant implied volatility is known as volatility smile. Depending on the underlying asset, the smile may be referred to as a smile, a frown, or a smirk. The volatility smile can be thought of as a measure of the correctness of the Black- 
Scholes formula - if the model correctly predicts the option price then the implied volatility would be relatively flat. And in fact there are two qualifying statements that can be made about that. First the implied volatility is relatively flat for options that are close to at-the-money levels, and second there is research suggesting that the volatility graph used to be much flatter than observed in the recent decades [27]. Those are topics that will be visited in more detail later. In the meantime, further discussion of using the Black-Scholes pricing formula to calculate implied volatility is warranted and this will require revisiting put-call parity.

Recall that the relationship known as put-call parity is defined as follows:

$$
c+K e^{-r T}=p+S_{0}
$$

where $S_{0}$ is the current asset price, $K$ is the strike price, $r$ is the risk-free interest rate, $T$ is the time to maturity, $c$ is the call premium, and $p$ is the put premium. Furthermore recall that this condition is necessary in an efficient market in order to prevent a riskless arbitrage opportunity (free lunch). Put-call parity does not dictate the way in which the option prices are determined, only that if the option premiums $c$ and $p$ do not satisfy the above relationship then a market maker can buy and sell in a way that guarantees riskless profit. It should be stated that in practice of course this relationship does not have to be strictly satisfied. First since the real world involves taxes and transaction costs, even if disparity exists it would have to be large enough to outweigh those costs. Second the real world also involves real time, and there is a difference between recognizing disparity and being able to act on it in a timely enough manner to profit from it before the market corrects the disparity. Consider the following example illustrating an important and subtle detail in the pricing of options in theory and in practice. 
Example 5.2 Let $\kappa$ represent the call option premium set by the market and $\pi$ represent the put premium as set by the market. Then let $c$ and $p$ represent the call and put option premiums respectively as calculated using the Black-Scholes formula. Then by put-call parity we have the following for the market price:

$$
\kappa+K e^{-r T}=\pi+S_{0}, \text { or } \kappa-\pi=S_{0}-K e^{-r T} \text {. }
$$

And we have the following for the Black-Scholes prices

$$
c+K e^{-r T}=p+S_{0} \text { or } c-p=S_{0}-K e^{-r T} \text {. }
$$

Since mathematically two expressions that are equal to a third are themselves equal (transitive property) we have

$$
\kappa-\pi=c-p .
$$

What this says is that regardless of the pricing method used, as long as it is consistent for calls and puts then the difference between the two option premiums will be the same. Furthermore, if the Black-Scholes formula is used to determine implied volatility and the market price for a call option then $\kappa=c$. This implies that $\pi=p$ as well using the implied volatility and the Black-Scholes formula, and that the implied volatility for a European call option is the same as it is for a European put option in the Black-Scholes framework.

So what drives the shape of the volatility skew in equity options in practice? Some research points to the obvious statement that the Black-Scholes formula itself may not be correct. This seems plausible since the mere use of it for calculating implied volatility gives the result previously mentioned, namely a nonconstant volatility, when the formula is based on the assumption that volatility is in fact constant. Admittedly it may be acceptable to use a formula that assumes constant volatility to show that volatility is not constant. But it does seem ironic at best to then continue to use the formula in order 
to theorize about the specific ways in which it is incorrect. It may be that the fact that doing so generates nonconstant volatilities is an indication that a different approach should be used, one which will not have such a violation as a result. This will be discussed more in detail shortly when alternatives to the constant volatility assumption are considered. But is there something at a practical level that indicates that the shape of the volatility smile for equity options is a real result that can be observed in the markets? Recall that the shape being considered is one where volatility is higher for out-of-themoney puts and in-the-money calls than for in-the-money puts and out-of-the-money calls. Interesting research and analysis has been done regarding this, and the more interesting ideas are related to a subtle reality in the minds of those buying and selling options.

Interestingly, the volatility smile for equity options has really only been observed in the pattern of option prices in the markets since the stock market crash in October 1987. Furthermore the pattern became more skewed after larger market downturns in October 1997 and August 1998. Prior to the 1987 crash implied volatility was very flat for equity options, and according to Rubenstein [27] although any wavering of market prices from a constant volatility in the 1970 s and 1980 s was financially insignificant, the variations could be considered statistically significant. Rubenstein refers to this phenomenon as "crashophobia" and suggests that traders began to price options in accordance with their fear of economic downturns.

Another interesting suggestion made by Hull [14] is that when stock prices decline, the debt to equity ratio for a company changes. This means that a company becomes more leveraged, and as a result of this leveraging the stock will be considered 
riskier and therefore the volatility will increase to account for this. At a point where the equity regains value and the leverage decreases, then a decreasing risk and volatility can be observed in the market prices.

Since the observation of volatility skew became prevalent after the 1987 market crash, alternatives to the standard Black-Scholes model have been developed. Even prior to that, some researchers sought out more robust and dynamic models that would allow for changing volatility over time. Many of these explore modifications to the BlackScholes formula to address nonconstant volatility in a continuous time framework. For example Duffie, et al [11] develop a jump diffusion model using instantaneous volatility as a function stock price and time among other variables. Hull and White [16] also explore the effects on asset option pricing when instantaneous volatility is itself defined as a stochastic process. More interesting in some respects are the earlier attempts to develop an option pricing model that use discrete time binomial models to address the volatility skew and incorporate nonconstant implied volatility to modify standard binomial asset pricing models to more fully capture this effect. It is a well known fact that the Black-Scholes formula is the continuous analog to the discrete binomial model for option pricing, and in fact is "a limiting case of the binomial formula for the price of a European option" (McDonald [21], p.375) when the number of periods $n \rightarrow \infty$ and the length of each interval $\Delta t \rightarrow 0$. In order to more fully investigate the implications of nonconstant volatility in option pricing, it will be necessary to develop the binomial model. Table 5.1 contains data from the Chicago Board Options Exchange for one month European call options. The implied volatility was then calculated using the Black-Scholes formula. As can be seen, the implied volatility varies with strike price. Following the 
method of Derman and Kani (1994), this implied volatility trend is used to interpolate the volatility at any given strike price in the modified binomial model. This allows for the development of an implied tree that will reflect both nonconstant volatility and observed option prices. First a discussion of a standard binomial pricing model is in order.

Table 5.1

\begin{tabular}{ccccccrrr}
$\mathrm{S}_{0}$ & $\mathrm{~K}$ & $\mathrm{r}$ & $\sigma^{2}$ & $\mathrm{~T}$ & $\sigma$ & Strike & $\begin{array}{c}\text { Implied } \\
\text { Volatility }\end{array}$ \\
\cline { 1 - 6 } 25.20 & 18.00 & 0.03 & 0.642 & 0.083 & 0.801 & 18.00 & 0.801 \\
25.20 & 19.00 & 0.03 & 0.308 & 0.083 & 0.555 & 19.00 & 0.555 \\
25.20 & 20.00 & 0.03 & 0.217 & 0.083 & 0.466 & 20.00 & 0.466 \\
25.20 & 21.00 & 0.03 & 0.145 & 0.083 & 0.381 & 21.00 & 0.381 \\
25.20 & 22.00 & 0.03 & 0.088 & 0.083 & 0.297 & 22.00 & 0.297 \\
25.20 & 23.00 & 0.03 & 0.001 & 0.083 & 0.035 & 23.00 & 0.035 \\
25.20 & 24.00 & 0.03 & 0.056 & 0.083 & 0.237 & 24.00 & 0.237 \\
25.20 & 25.00 & 0.03 & 0.052 & 0.083 & 0.229 & 25.00 & 0.229
\end{tabular}

Figure 5.1

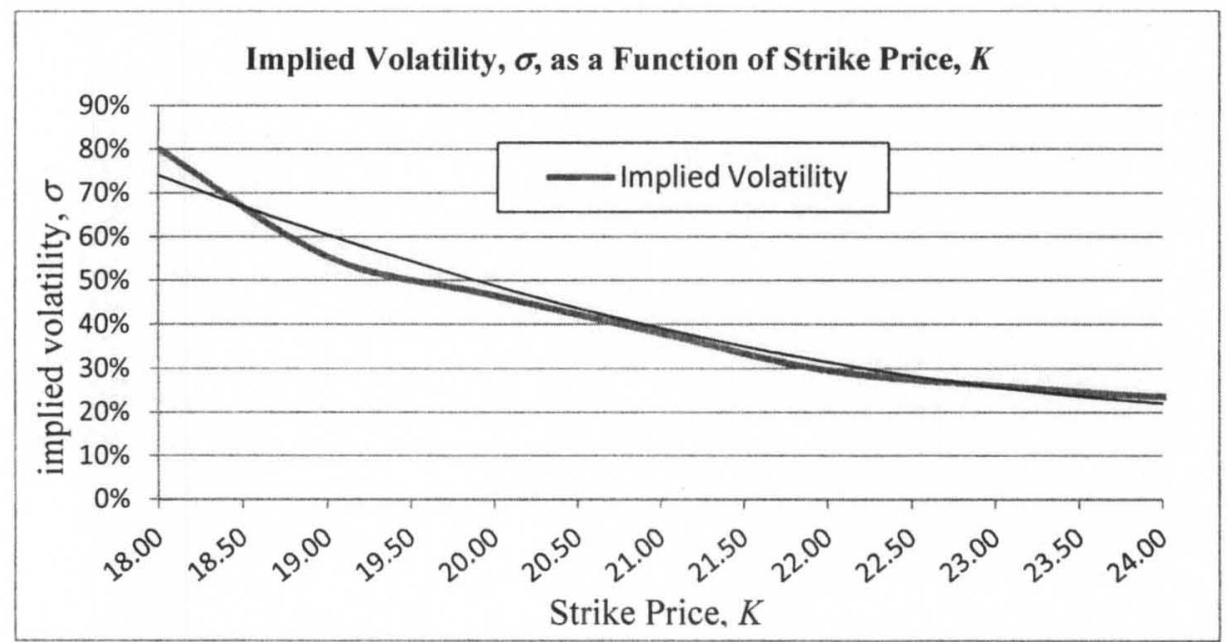

In a standard binomial option pricing model, the current asset price, $S_{0}$, volatility, $\sigma$, and risk-free interest rate, $r$, are known at an initial node at time zero. A lattice work is developed where there are only two possible values for the asset price at the end of the subsequent time interval of length $h$, each represented by a new node. Specifically the 
asset price either increases by a known factor $u$, with a known probability, or decreases by a known factor $d$, with a known probability. This pattern continues from each of these nodes to a set of new nodes at yet another subsequent level. There are a number of standard binomial models, but for the purpose here we will use the Cox-Ross-Rubenstein Binomial Model (1979), which will allow for the calculation of future asset prices as well as the value at time $t_{0}$ of an option expiring at time $t_{n}$. This model will be referred to as the CRR model from here on. The focus initially will be on determination of future asset prices, then move to valuing a European call option expiring at $t_{n}$ with strike price $K=S_{0}$. First there is a need to define some of the system parameters for this model and develop the fundamental mathematical and probabilistic relationships.

Definition 5.1 Risk neutral probability is the probability that an asset price will go up so that the stock earns the risk-free interest rate. The risk-neutral probability is denoted as $p^{*}$.

From the above definition it can be seen that the risk-neutral term in the definition does not refer to investor preference, but simply to the idea that there is a probability that an asset price will increase over a given interval of time, $h$, in a risk-neutral market. Mathematically this means that for some upward transition factor $u$ and some downward transition factor $d$, the following relationship must hold.

Equation 5.1 $S_{t+h}=e^{r h} S_{t}=p^{*} u S_{t}+\left(1-p^{*}\right) d S_{t}$ In other words the expected value of the asset at time $t+h$ is the same as the value of the asset growing at the risk free rate, $r$. Solving Equation 5.1 for $p^{*}$ and dividing by the asset price, $S_{t}$, gives the following equation for the risk-neutral probability, $p^{*}$, of an upward move. 
Equation $5.2 p^{*}=\frac{e^{r h}-d}{u-d}$

In order to develop the lattice for a binomial model it is also necessary to determine $u$ and $d$. The risk-neutral probability $p^{*}$ addresses the likelihood of an up or down move, but does not address the magnitude of the move. As a result there is another component of uncertainty that needs to be incorporated into the binomial model. The CRR model uses the standard deviation of the continuously compounded return on the asset, otherwise known as $\sigma$, to aid in determining the actual uncertainty in the magnitude of the up and down factors by which the asset price changes. Since the model is dealing with a time interval $h$, the relevant uncertainty is equivalent to $e^{ \pm \sigma \sqrt{h}}$. This leads to the following relationships and values for $u$ and $d$ in the presence of uncertainty for the CRR model.

Equation 5.3 (i) $u S_{t}=S_{t} e^{\sigma \sqrt{h}} \rightarrow u=e^{\sigma \sqrt{h}}$

(ii) $d S_{t}=S_{t} e^{-\sigma \sqrt{h}} \rightarrow d=e^{-\sigma \sqrt{h}}$

Now everything necessary to construct a CRR binomial tree is available. The tree will then be used to obtain the option price over period $T$ using $k$ intervals of length $h$. This is equivalent to saying that $h=T / k$ and for the purpose here and clarity of demonstration, we will let $T=3$ years and $h=1$ year without loss of generality. In addition let the asset price at time 0 be $S_{0}=100$, the risk-free rate $r=2.956 \%$ (so that $e^{r}=$ 1.03 ), the initial (and constant) volatility $\sigma=10 \%$, and the dividend rate be zero (no dividend payments). For ease of reference consider Figure 5.2 below, where the nodes in a three period CRR binomial tree will be denoted by the letters A through J. Using the references in Figure 5.2, the starting asset price will be $S_{A}=S_{0}$, which was set at 100, the asset price at time $t=1$ will be $S_{B}$ for an upward move and $S_{C}$ for a downward move, and so on for the remaining levels of the tree. Using Equations 5.2 and 5.3 the values of $u, d$, 
and $p^{*}$ are determined as follows.

$$
\begin{aligned}
& u=e^{\sigma \sqrt{h}}=e^{0.10 \sqrt{1}}=1.1052 \\
& d=e^{-\sigma \sqrt{h}}=e^{-0.10 \sqrt{1}}=0.9048 \\
& p^{*}=\frac{e^{r h}-d}{u-d}=\frac{1.03-0.9048}{1.1052-0.9048}=0.625 \\
& l-p^{*}=0.375
\end{aligned}
$$

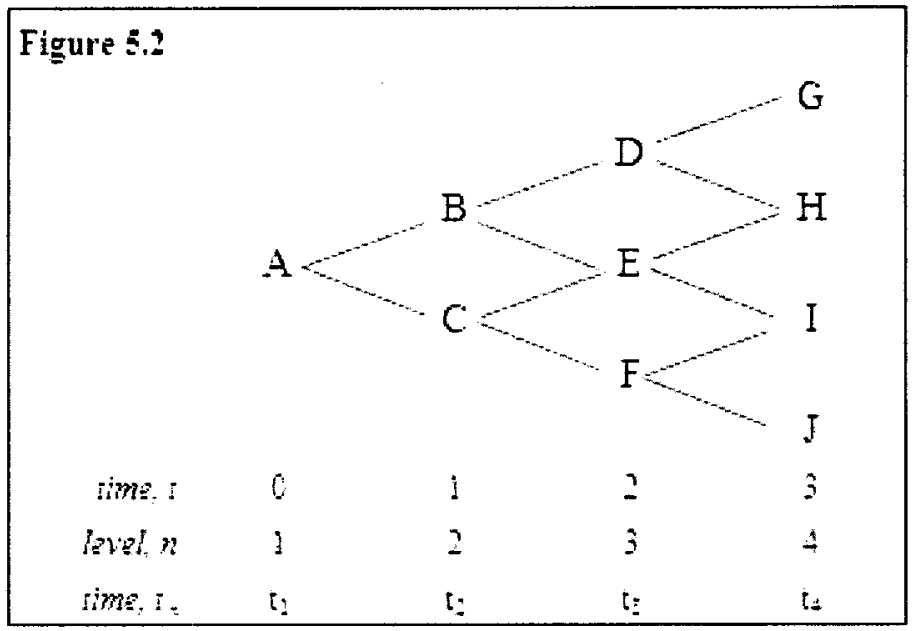

Using the tree in Figure 5.2 along with the calculations above, the three period CRR binomial tree of asset prices can be developed in full as follows, and shown in Figure 5.3.

$$
\begin{aligned}
& S_{B}=u S_{A}=1.1052(100)=110.52 \\
& S_{C}=d S_{A},=0.9048(100)=90.48 \\
& S_{D}=u S_{B}=1.1052(110.52)=122.15 \\
& S_{E}=d S_{B}=0.9048(110.52)=100.00 \text { or } S_{E}=u S_{B C}=1.1052(90.48)=100.00 \\
& S_{F}=d S_{C},=1.1052(90.48)=81.87 \\
& S_{G}=u S_{D},=1.1052(122.15)=135.00 \\
& S_{H}=d S_{D},=0.9048(122.15)=110.52 \text { or } S_{H}=u S_{E},=1.1052(100.00)=110.52 \\
& S_{I}=d S_{E},=0.9048(100.00)=90.48 \text { or } S_{I}=u S_{F},=1.1052(81.87)=90.48 \\
& S_{J}=d S_{F},=0.9048(81.87)=74.07
\end{aligned}
$$


Note that the nature of $u$ and $d$, which are reciprocals, allows for the lattice style known as a recombining tree, since there are two ways to calculate intermediate nodes, a fact that agrees nicely with the binomial nature of the tree. So under the CRR binomial asset model, four possible values of the asset at time $t=3$ are possible as shown in Figure 5.3, but thus far only the possible asset prices as determined by $u$ and $d$, and not their likelihoods have been determined.

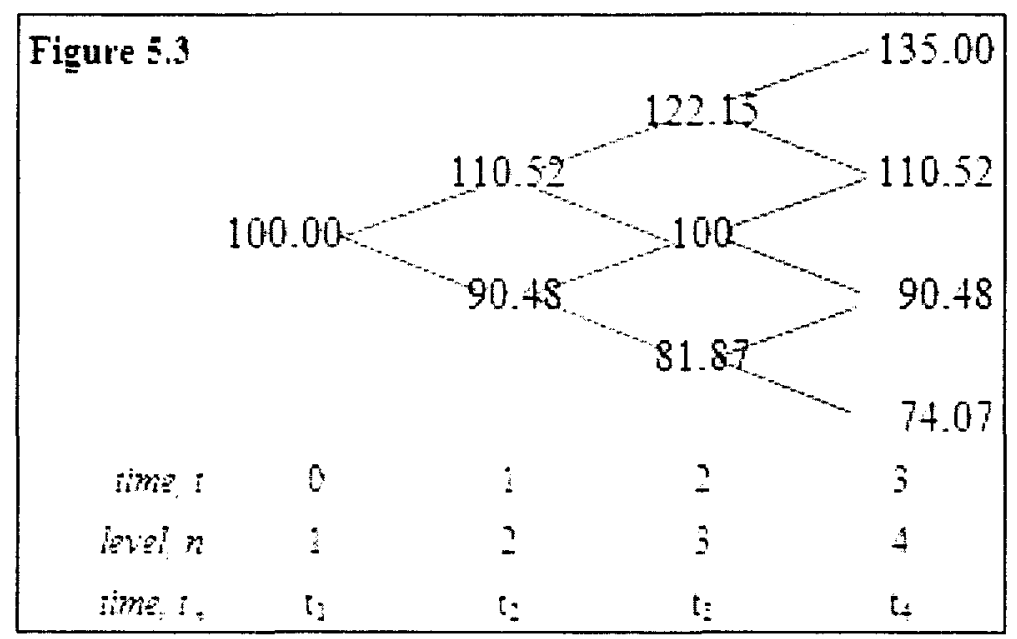

Since the volatility is constant at $10 \%$, and the values of $u$ and $d$ depend only on $\sigma$ and $h$, it follows that the probability of an upward move from any node at any level of the tree is also constant, namely $p^{*}=0.625$. Similarly then the probability of a downward move from any node at any level of the tree is constant, namely $1-p^{*}=0.375$. So the probability of reaching the top node at level $\mathbf{n}$ is simple $\left(p^{*}\right)^{n}$ and the probability of reaching the bottom node is $\left(1-p^{*}\right)^{n}$. Similarly then to reach the $j^{\text {th }}$ node below the top at any level of the tree, exactly $j$ downward movements are required, and there are $n$ ways to do so. For example node $H$ is one node below the top node when $n=3$, so one downward movement and two upward movements are required. This lone downward movement can occur in the transition to level $n=2$, level $n=3$, or level $n=4$. This means that there are 
three paths to node $\mathrm{H}$, namely $A-B-D-H, A-B-E-H$, and $A-C-E-H$, each with a probability of $\left(p^{*}\right)^{2}\left(1-p^{*}\right)$. So the overall probability of reaching node $\mathrm{H}$ is given by $3\left(p^{*}\right)^{2}\left(1-p^{*}\right)$. Figure 5.4 illustrates the probability of being at any given node in the binomial tree. These resulting probabilities are recognizable as standard binomial probabilities, such that the probability of reaching the $j^{\text {th }}$ node from the top of level $n$ is given in Equation 5.4 .

Equation 5.4 $\operatorname{Pr}\left(\right.$ reaching $j^{\text {th }}$ node from top in level $\left.n\right)=\left(\begin{array}{c}n-1 \\ j\end{array}\right) \mathrm{p}^{*(\mathrm{n}-1-\mathrm{j})}\left(1-\mathrm{p}^{*}\right)^{\mathrm{j}}$ where $\left(\begin{array}{c}n-1 \\ j\end{array}\right)$ is the standard combination function defined as $\left(\begin{array}{c}n-1 \\ j\end{array}\right)=\frac{(n-1) !}{(n-1-j) ! j !}$, describing the number of ways $j$ items can be selected from a group of $n-1$. This function is also referred to a choosing function or binomial coefficient.

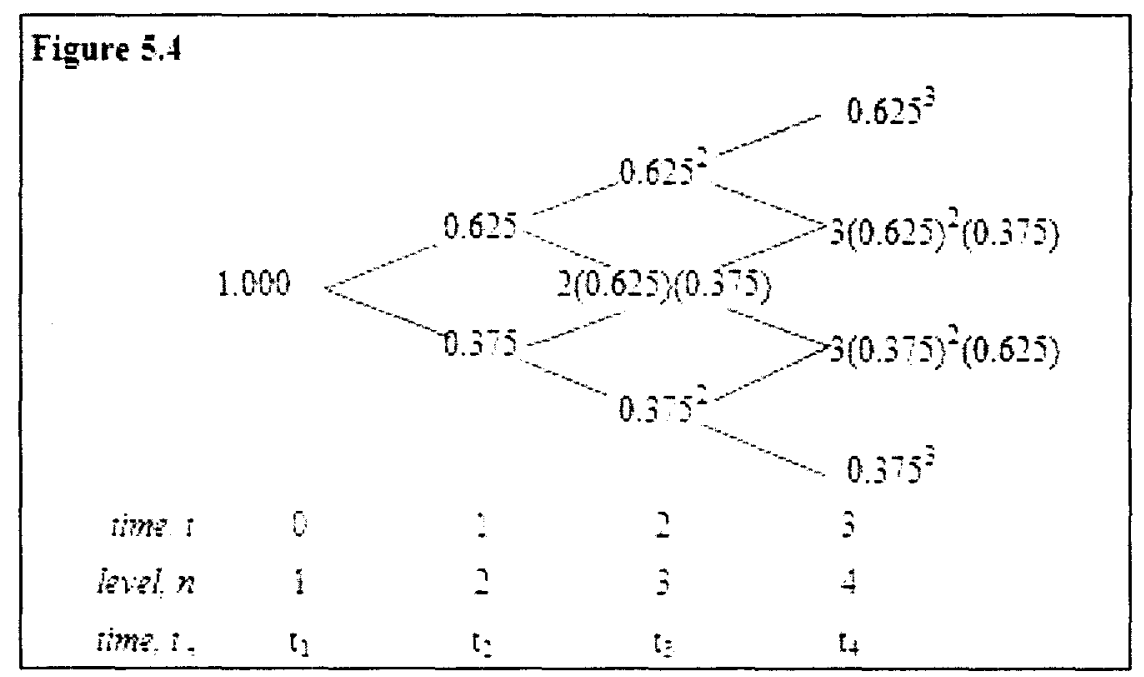

In this binomial framework both the probability of reaching a particular node and the asset price at that node are known. The final stage that will allow for the transition from asset prices and associated probabilities to option prices at time $t=0$ for a given strike price, $K$, expiring at $t_{n}$ is the consideration of the time value of money. 
Recall that the payoff for a European call option expiring at time $T$ with strike price $K$ is given by $C=\max \left(S_{T}-K, 0\right)$. Consider then an at-the-money European call option on the asset described above, such that $K=S_{0}$. Using the asset prices in Figure 5.3 , the payoff at expiration can be calculated for each of the four nodes at time $t_{n}$ using this definition above. The no arbitrage option premium at time $t=0$ will be the expected value of all potential payoffs, weighted by the node-specific probability then discounted back to time $t=0$. In the present example the call option expires at time $t=3$ years and the strike price is $K=100$. Let $C_{M}$ denote the value of the call option at node $M$ in the tree. Then the value of the call at $t=3$ is equal to the potential payoffs at $t_{4}$ (level 4 in the tree), denoted by $C_{G}, C_{H}, C_{l}$, and $C_{J}$ corresponding to nodes $G, H, I$, and $J$ in Figure 5.2 respectively. Then for the European call option being considered we have the following potential payoffs at expiration $t=3$.

$$
\begin{aligned}
& C_{G}=\max (135.00-100.00,0)=35.00, \\
& C_{H}=\max (110.52-100.00,0)=10.52, \\
& C_{I}=\max (90.48-100.00,0)=0.00, \text { and } \\
& C_{J}=\max (74.07-100.00,0)=0.00
\end{aligned}
$$

To obtain the call option premium at $t_{0}$ it is necessary to weight these payoffs with their path dependent probabilities and discount them. This can be accomplished one level of the tree at a time, so that the value of the same option at $t=2$ is given by $C_{D}, C_{E}$, and $C_{F}$ as follows.

$$
\begin{aligned}
& C_{D}=\left[p^{*} C_{G}+\left(1-p^{*}\right) C_{H}\right] e^{-r h}=[0.625(35.00)+0.375(10.52)] / 1.03=25.07, \\
& C_{E}=\left[p^{*} C_{H}+\left(1-p^{*}\right) C_{I}\right] e^{-r h}=[0.625(10.52)+0.375(0.00)] / 1.03=6.38, \text { and } \\
& C_{F}=\left[p^{*} C_{I}+\left(1-p^{*}\right) C_{J}\right] e^{-r h}=[0.625(0.00)+0.375(0.00)] / 1.03=0.00
\end{aligned}
$$


Similarly for $t=0$ and $t=1$, we have the following call values.

$$
\begin{aligned}
& C_{B}=\left[p^{*} C_{D}+\left(1-p^{*}\right) C_{E}\right] e^{-r h}=[0.625(25.07)+0.375(6.38)] / 1.03=17.53, \\
& C_{C}=\left[p^{*} C_{E}+\left(1-p^{*}\right) C_{F}\right] e^{-r h}=[0.625(6.38)+0.375(0.00)] / 1.03=3.87, \text { and } \\
& C_{A}=\left[p^{*} C_{B}+\left(1-p^{*}\right) C_{A}\right] e^{-r h}=[0.625(17.53)+0.375(3.87)] / 1.03=12.05
\end{aligned}
$$

So in this example the value at time $t=0$ of a European call option expiring at $t=3$ with a strike price $K=100$ is 12.05 . Notice that the recombining tree is centered along the atthe-money option price $S_{0}$, and that for nodes below the center, the call option value is 0 . Recall that the payoff for a European put option is given by $P=\max \left(K-S_{T}, 0\right)$, and that above the center of the tree put options will have a value of 0 . Figure 5.5 shows the CRR binomial option pricing model for the current example.

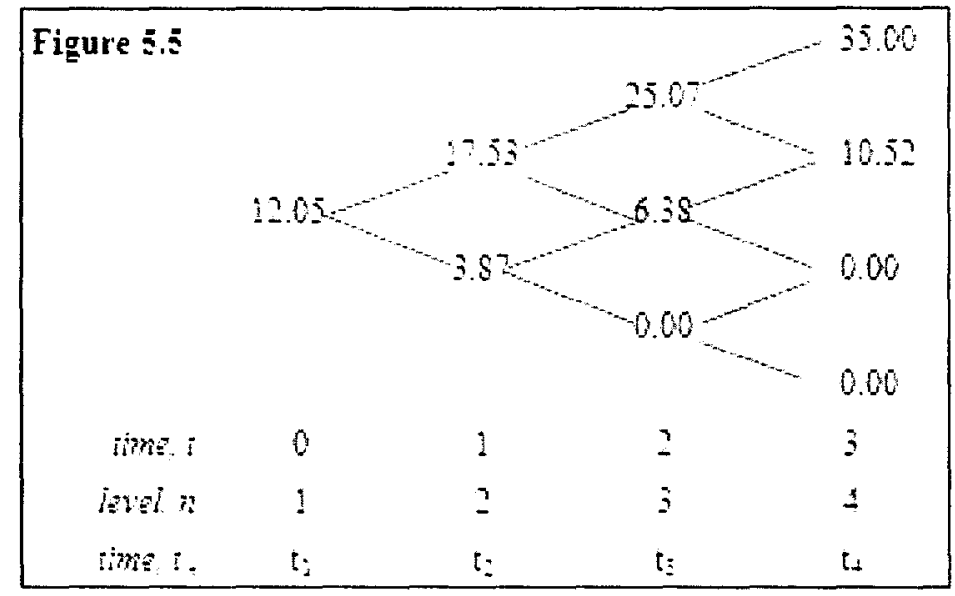

Although this model assumes a constant volatility of $10 \%$, the framework can be generalized in order to recalibrate the asset prices along the tree using the implied volatilities from observed market data. The implied tree will then correctly reflect the changing implied volatility (i.e. the volatility skew) observed in the market for options at different strike prices for the same asset. Several papers of interest have approached this topic, namely Rubenstein (1994), Dupire (1994), and Derman and Kani (1994). The remainder of this paper will focus on the method developed by Derman and Kani in The 
Volatility Smile and Its Implied Tree, as mentioned previously. In order to do so a generalized approach to the CRR binomial model will be illustrated, and it will be shown that the method of Derman and Kani is analogous to this generalized approach while allowing for nonconstant volatility indicated in observed market prices for options. Derman and Kani develop thorough notation describing known and unknown values of various factors at time $t_{n}$, as well as location and movement along the tree. This notation will be described and adopted showing its effectiveness in the CRR model before going into more detail regarding its use in Derman and Kani's modifications.

Definition 5.2 Let $(n, i)$ denote the $i^{\text {th }}$ node of the tree at the $n^{\text {th }}$ level of the tree. In the example shown in Figure 5.2 node $\mathrm{F}$ can be denoted by $(3,1)$, node $\mathrm{E}$ by $(3,2)$, node $\mathrm{D}$ by $(3,3)$, node $\mathrm{J}$ by $(4,1)$ and so on.

Definition 5.3 Let $s_{i}$ denote the known asset price at node $(n, i)$ as well as the strike price for options expiring at $n+1$.

Definition 5.4 Let $S_{i}$ denote the asset price at node $(n+1, i)$. In standard models this is a known value, but in the Derman and Kani modification it will be determined by induction.

Definition 5.5 Let $F_{i}$ denote the known forward price at level $n+1$ of the known asset price $s_{i}$ at level $n$, then $F_{i}=s_{i} e^{r \Delta t}$.

Definition 5.6 Let $p_{i}$ denote the risk-neutral transition probability from node $(n, i)$ to node $(n+1, i+1)$. Note that this is an up transition.

Figure 5.6 shows how the above notation applies to a binomial tree at levels $n$ and $n+1$. Note that the tree is representative only and is not meant to be the full tree for those levels. 


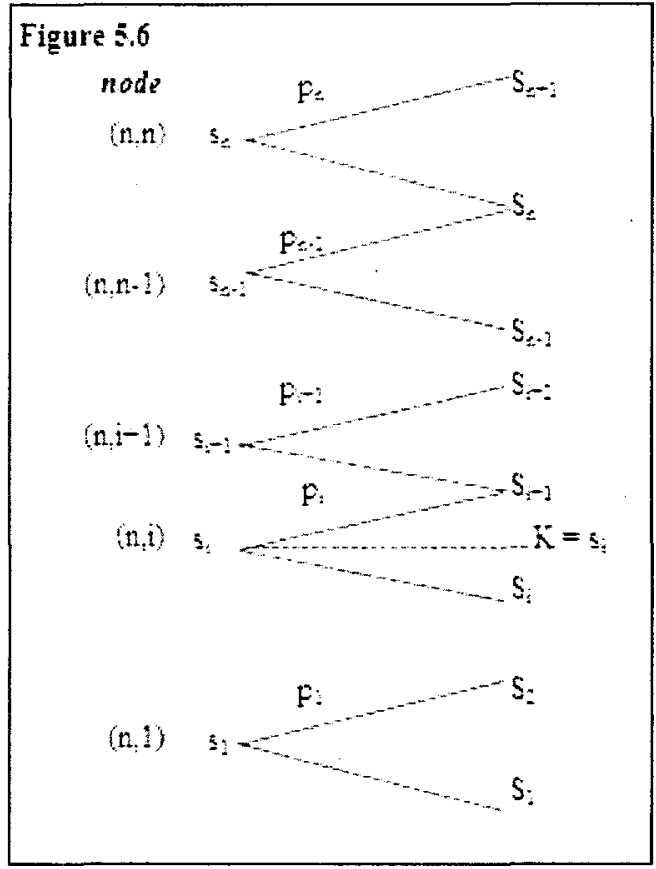

Using this notation, we can reexamine the previous CRR option value example. Consider that the final dollar value of the option is based solely on the payoff values at $t$ $=3$. These payoffs are weighted by node-specific path probabilities and appropriately discounted to $t=0$. As a result if the node-specific factors can be determined for all level $n$ nodes that incorporate both the node-specific probabilities and discounting, then the payoffs for level $n+1$ can be used to quickly calculate the option value at $t=0$. In the present example $e^{r}=1.03, S_{0}=100, \sigma=20 \%$, the period interval $h=1$ year, $T=3$ years, $K=100$, and $p^{*}=0.625$. When $n=3$ there are three corresponding asset prices: node $(3,1)=s_{1}=81.87 ;$ node $(3,2)=s_{2}=100.00 ;$ and the top node $(3,3)=s_{3}=122.15$ that are known using the calculated factors $u$ and $d$. As determined earlier, the probability of reaching $s_{3}$ is given by the following as $(0.625)^{2}=0.391$, and the probability of reaching $s_{1}$ is given by the following as $(0.375)^{2}=0.141$. To determine the probability of reaching $s_{2}$ we have to use Equation 5.4 . 


$$
\left(\begin{array}{c}
n-1 \\
j
\end{array}\right) p^{*(n-1-j)}\left(1-p^{*}\right)^{j}=\left(\begin{array}{l}
2 \\
1
\end{array}\right) p^{*}\left(1-p^{*}\right)=2(0.625)(0.375)=0.469
$$

Knowing that the aim is to discount the payoff for exercising the option at level $n+1$, it is clear that to get back to level 1 , where $t=0$, we need to discount each of these quantities factors for two periods. Let $\lambda_{i}$ denote the resulting transition probabilities discounted for $n-1$ periods at the riskless rate at node $(n, i)$. Then we have $\lambda_{1}=0.133, \lambda_{2}=0.442$, and $\lambda_{3}=0.368$. Consider the following definition

Definition 5.7 The Arrow-Debreu price, $\lambda_{i}$, is the sum of the products of the transition probabilities discounted at the riskless rate back to node $(1,1)$ at each node in each path leading to $(n, i)$ over all paths from the root node $(1,1)$ of a binomial tree to node $(n, i)$. In the case of constant volatility, and therefore constant factors $u$ and $d$, these values are easily calculated as shown above. So the only requirement at present is to show that it applies to the standard CRR model. However Derman and Kani develop a method using forward induction to calculate these factors using the volatility smile implied by the market prices for the options, as will be shown later.

We can then calculate the Arrow-Debreu price at every node in each level prior to level $n$ using the same method. Figure 5.7 shows the Arrow-Debreu price tree for the current example. Note that this factor is 1.000 at node $(1,1)$, since at $t=0$ the asset price is known and transition, uncertainty, and discounting do not need to be considered. The goal is to price a call option expiring when $n=4$, so of interest here is the Arrow-Debreu price at each node when $n=3$, which is the discounted probability of being at node $(3, i)$. To calculate the call at $t=0$, we only need to discount the probability-weighted payoff at each node $(4, j)$ by an additional period. Figure 5.8 shows the Arrow-Debreu prices when $n=3$ and the payoffs for the European call option with a strike price of 100 expiring 


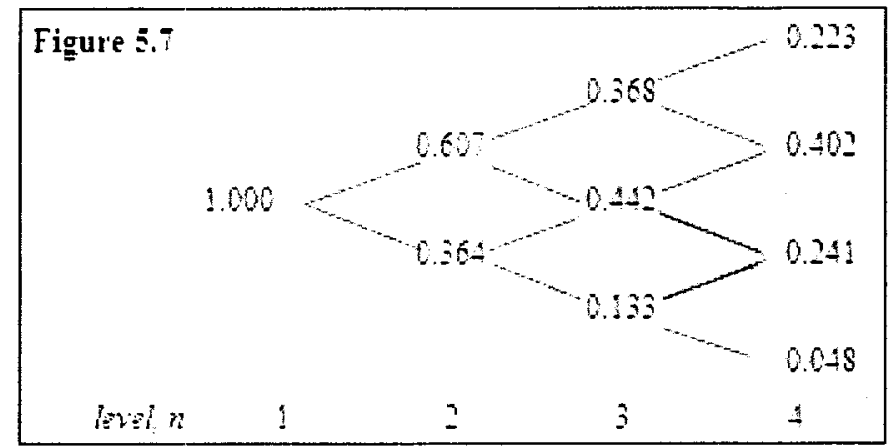

expiring at $n=4$. The value of this option at $t=0$ is then

$0.442\left[\frac{0.625}{1.03}(10.52)\right]+0.368\left[\frac{0.375}{1.03}(10.52)\right]+0.368^{*}\left[\frac{0.625}{1.03}(35)\right]=12.05$.

Note that the factors $\frac{0.625}{1.03}$ and $\frac{0.375}{1.03}$ are the factors that we multiply by the level 3 ArrowDebreu prices to obtain the level 4 Arrow-Debreu prices in Figure 5.7. Also note that we use only the nonzero call payoffs that result when $S_{j}>K$.

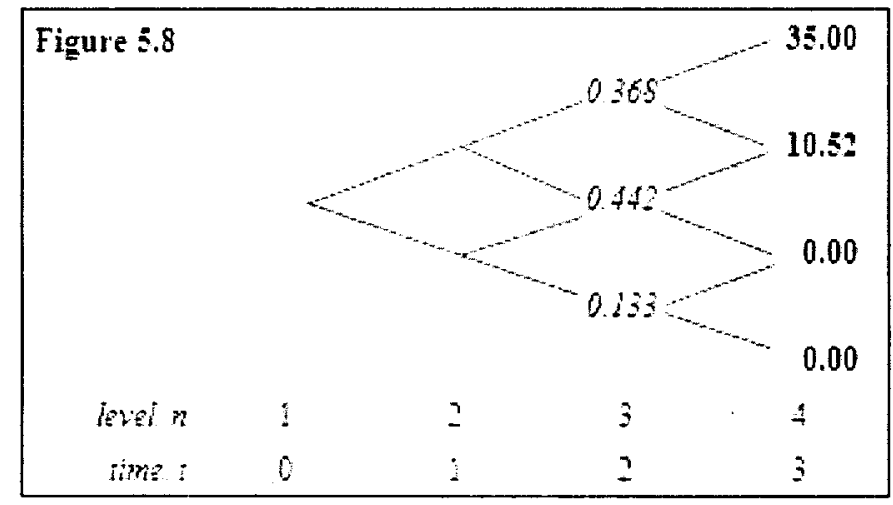

The value of 12.05 is identical to the value originally calculated using the standard procedure.

Definition 5.8 Let $C\left(K, t_{n+l}\right)$ and $\boldsymbol{P}\left(K, t_{n+1}\right)$ denote the value today for a call option and put option, respectively, with strike price $K$ that expires at $t_{n+l}$.

Recall the binomial tree in Figure 5.2 (reproduced below). Using the notation introduced above, and substituting the value of the call option can be written in the following way. 


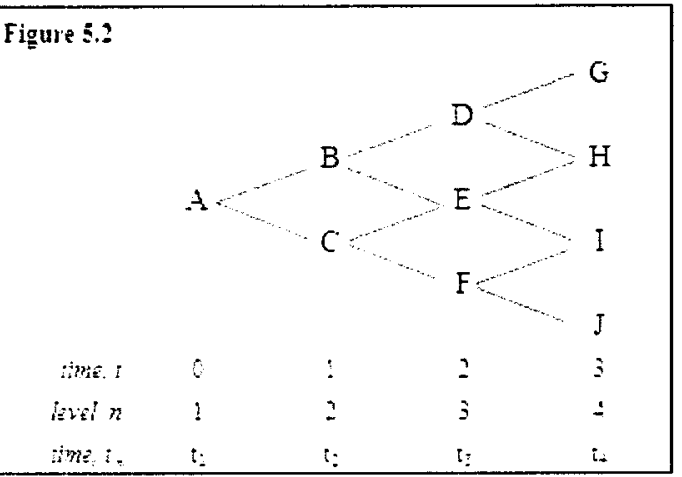

$\left[\lambda_{1}\left(1-p^{*}\right) C_{J}+\lambda_{1} p^{*} C_{l}+\lambda_{2}\left(1-p^{*}{ }_{2}\right) C_{I}+\lambda_{2} p^{*} C_{H}+\lambda_{3}\left(1-p^{*}{ }_{3}\right) C_{H}+\lambda_{3} p^{*}{ }_{3} C_{G}\right] e^{-r h}$

The resulting summation formula describing this relationship is given as Equation 5.5. In general the length of the period $h$ is also the change in $t$ and can be written as $\Delta t$.

Equation $5.5 C\left(K, t_{n+1}\right)=\sum_{j=1}^{n}\left[\lambda_{j} p_{j}^{*}+\lambda_{j+1}\left(1-p_{j+1}^{*}\right)\right] e^{-r h} \max \left(S_{T}-K, 0\right)$

Now consider the binomial model proposed by Derman and Kani. The asset price at $t=0$ and the option prices are known from the market data. Using the Black-Scholes formula the implied volatilities can be calculated, resulting in a relationship between the strike price and volatility (volatility skew) that allows for option prices to be interpolated for any strike price. Assuming that the initial volatility is that for an at-the-money European call option, the implied tree is developed starting at node $(1,1)$ and using induction the implied asset prices at each node in the tree are calculated. The result being a binomial tree that correctly reflects observed option prices in the market and the volatility skew. The known transition probabilities are risk neutral, which means that the expected value of the asset at any node $(n, i)$ in the next period is equal to the forward price, resulting in the following equations.

Equation $5.6 F_{i}=p_{i}^{*} S_{i+1}+\left(1-p_{i}^{*}\right) S_{i}$

Solving Equation 5.6 for $p_{i}^{*}$ results in the following. 
Equation $5.7 p_{i}^{*}=\frac{F_{i}-s_{i}}{S_{i+1}-S_{i}}$

In the CRR binomial model, $p_{i}^{*}$ was constant, but here it can be seen that it depends on the position in the tree. This makes sense because $p_{i}^{*}$ is defined to be the probability of an upward transition from a node for a given volatility, and in the modified tree the volatility is known to be changing.

Since Derman and Kani are using a model that is anchored at level $\mathrm{n}$ with known forward prices, known implied volatilities, and known Arrow-Debreu prices, the following equation reflects the value of a call option with strike price $K$ expiring at $t_{n-1}$. Equation $5.8 C\left(s_{i}, t_{n+1}\right)=\sum_{j=1}^{n}\left[\lambda_{j} p_{j}^{*}+\lambda_{j+1}\left(1-p_{j+1}^{*}\right)\right] e^{-r \Delta t} \max \left(S_{j+1}-s_{i}, 0\right)$ Since the strike price $K$ is set equal to $s_{i}$, the known asset price at $(n, i)$, consider what happens with regard to the transition to the first up node $S_{i+1}$. The above summation can be simplified by multiplying Equation 5.8 by $e^{r t}$ then examining the summation term by term beginning with the first in-the-money up move, in other words when $j=i$, then the index of the remaining summation will run from $j=i+1$ to $j=n$ as shown below.

\section{Equation 5.9}

$$
\begin{aligned}
& C\left(s_{i}, t_{n+1}\right) e^{r t}=\lambda_{i} p_{i}^{*}\left(S_{i+1}-s_{i}\right)+\lambda_{i+1}\left(1-p_{i+1}^{*}\right)\left(S_{i+1}-s_{i}\right)+\lambda_{i+1} p_{i+1}^{*}\left(S_{i+2}-s_{i}\right)+ \\
& \lambda_{i+2}\left(1-p_{i+2}^{*}\right)\left(S_{i+2}-s_{i}\right)+\lambda_{i+2} p_{i+2}^{*}\left(S_{i+3}-s_{i}\right)+\lambda_{i+3}\left(1-p_{i+3}^{*}\right)\left(S_{i+3}-s_{i}\right)+\ldots+ \\
& \lambda_{n} p_{n}^{*}\left(S_{n}-s_{i}\right)+\lambda_{n+1}\left(1-p_{n+1}^{*}\right)\left(S_{n+1}-s_{i}\right) .
\end{aligned}
$$

Notice that the first term in Equation 5.9 is the contribution of the overall value resulting from the first in-the-money option, and the remaining terms are equivalent to Equation 5.8 with a change of index described above. Now consider the sum given by the second and third terms in Equation 5.9, specifically

$$
\lambda_{i+1}\left(1-p_{i+1}^{*}\right)\left(S_{i+1}-s_{i}\right)+\lambda_{i+1} p_{i+1}^{*}\left(S_{i+2}-s_{i}\right) .
$$


By distributing we have

$$
\lambda_{i+1}\left(1-p_{i+1}^{*}\right) S_{i+1}-\lambda_{i+1} s_{i}+\lambda_{i+1} p_{i+1}^{*} s_{i}+\lambda_{i+1} p_{i+1}^{*} S_{i+2}-\lambda_{i+1} p_{i+1}^{*} s_{i}
$$

By collecting like terms and applying Equation 5.6, we have

$$
\lambda_{i+1}\left(1-p_{i+1}^{*}\right) S_{i+1}+\lambda_{i+1} p_{i+1}^{*} S_{i+2}-\lambda_{i+1} s_{i}=\lambda_{i+1} F_{i+1}-\lambda_{i+1} s_{i}=\lambda_{i+1}\left(F_{i+1}-s_{i}\right)
$$

Similar results follow for the remaining terms up to $j=n$. This yields the following overall results.

Equation $5.10 C\left(s_{i}, t_{n+l}\right) e^{r t}=\lambda_{i} p_{i}^{*}\left(S_{i+1}-s_{i}\right)+\sum_{j=i+1}^{n} \lambda_{j}\left(F_{j}-s_{i}\right)$

Since the forward prices and option prices, $F_{i}$ and the $C\left(s_{i}, t_{n+1}\right)$ respectively, are known, we can solve 5.6 and 5.10 simultaneously for $S_{i+1}$ and $p_{i}^{*}$ with the following result.

Equation $5.11 S_{i+1}=\frac{s_{i}\left[e^{r \Delta t} C\left(s_{i}, t_{n+1}\right)-\Sigma\right]-\lambda_{i} s_{i}\left(F_{i}-s_{i}\right)}{\left[e^{r \Delta t} C\left(s_{i}, t_{n+1}\right)-\Sigma\right]-\lambda_{i}\left(F_{i}-s_{i}\right)}$ where $\Sigma$ denotes $\sum_{j=i+1}^{n} \lambda_{j}\left(F_{j}-s_{i}\right)$ and $p_{i}^{*}=\frac{F_{i}-s_{i}}{s_{i+1}-s_{i}}$

Using this relationship for call options, the implied asset prices, $S_{j}$, and riskneutral probabilities, $p_{j}^{*}$, for each node in upper portion of the binomial tree at the $(n+1)^{\text {th }}$ level can be completed, assuming there is a value $S_{i}$ for an initial node. At any given $(n+1)^{\text {th }}$ level of the tree, the number of nodes is either even or odd. Based on the centering condition described before, if the $(n+1)^{\text {th }}$ level has an odd number of nodes, the $S_{i}$ used will be the central node of the tree (i.e. the CRR spot price). Due to the recombining nature of the tree and the fact that the central node in an odd level is equal to the CRR spot price, the nodes above can be calculated using Equations 5.7 and 5.11. When the $(n+1)^{\text {th }}$ level is even, $S_{i}$ will be the node just below the center of the tree and $S_{i+1}$ will be the node just above the center, where $i=(n+1) / 2$. Again based on the 
centering condition, the CRR spot price $s_{i}$ is the geometric mean of $S_{i}$ and $S_{i+1}$, namely $S_{i}=\frac{s_{i}^{2}}{s_{i+1}}$. Substituting this result into Equation 5.11 gives the following result for calculating the asset price at node $\left(n+1, \frac{n}{2}\right)$ where $n$ is even.

Equation 5.12 $S_{i+1}=\frac{s_{i}\left[e^{r \Delta t} C\left(s_{i}, t_{n+1}\right)+\lambda_{i} s_{i}-\Sigma\right]}{\lambda_{i} F_{i}-e^{r \Delta t} C\left(s_{i}, t_{n+1}\right)+\Sigma}$, where $\Sigma$ denotes $\sum_{j=i+1}^{n} \lambda_{j}\left(F_{j}-s_{i}\right)$

Once the upper half of the tree at the $(n+1)^{\text {th }}$ level has been completed using call prices, then we complete the lower half of the tree in a similar manner using the known put prices. Recall that the payoff at time $T$ for a European put option expiring at $T$ with strike price $K$ is given by $P=\max \left(K-S_{T}, 0\right)$. So the asset price at the node $(n+1, i)$ in the $(n+1)^{\text {th }}$ level can be determined from the known asset price at the known upper node $(n+1, i+1)$ using Equation 5.13. The basis of Equation 5.13 is analogous to that of Equation 5.12 and can be found in the appendix.

Equation $5.13 S_{i}=\frac{s_{i+1}\left[e^{r \Delta t} P\left(s_{i}, t_{n+1}\right)-\Sigma\right]+\lambda_{i} s_{i}\left(F_{i}-s_{i+1}\right)}{\left[e^{r \Delta t} P\left(s_{i}, t_{n+1}\right)-\Sigma\right]-\lambda_{i}\left(F_{i}-s_{i+1}\right)}$, where $\Sigma=\sum_{j=1}^{i-1} \lambda_{j}\left(s_{i}-F_{j}\right)$

Using the above methods, the implied tree of asset prices can be constructed node by node down to $i=1$ that accurately represents the volatility skew and market option prices at each level of the tree.

To demonstrate this we will construct a theoretical example. Suppose option prices on a stock with current price 50 are collected and the implied volatilities are calculated. Furthermore suppose that the resulting volatility smile indicates that the atthe-money options have an implied volatility of 0.15 , and that analysis of the smile indicates the relationship between implied volatility and strike price is as follows. For every two dollar change in strike price, the implied volatility changes by 0.004 . When the strike price $K$ is below the current price then the volatility increases and when $K$ is above 
the current price the volatility decreases. This relationship is described in Equation 5.14. Equation 5.14 $\sigma=0.15+0.004\left(\frac{50-K}{2}\right)$

Let the risk-free interest $r=2.956 \%$ and consider a binomial model where for ease of illustration $h=1$ year. Then we have $e^{r h}=1.03$. We will now construct a threeperiod binomial tree of implied asset prices using the volatility smile in Equation 5.14 to interpolate implied volatilities for any strike price. For clarity refer to Figure 5.2 reproduced below. Note that the risk-neutral probability under the CRR model will be denoted as $p$, whereas the risk-neutral probability associated with a particular node under the Derman and Kani model will be denoted $p_{N}^{*}$ for node $N$. We will begin by completing section of the tree containing nodes $A, B$, and $C$. Using the call option methods previously discussed, the upper section of tree will be completed. Then using the put option methods the lower section of the tree will be completed. By completed it is meant that the implied asset price, implied volatility, risk-neutral probability of an up transition, and the ArrowDebreu price for each node will be determined. In the interest of space, these values will be calculated for representative nodes on the tree, with the remaining values supplied as needed.

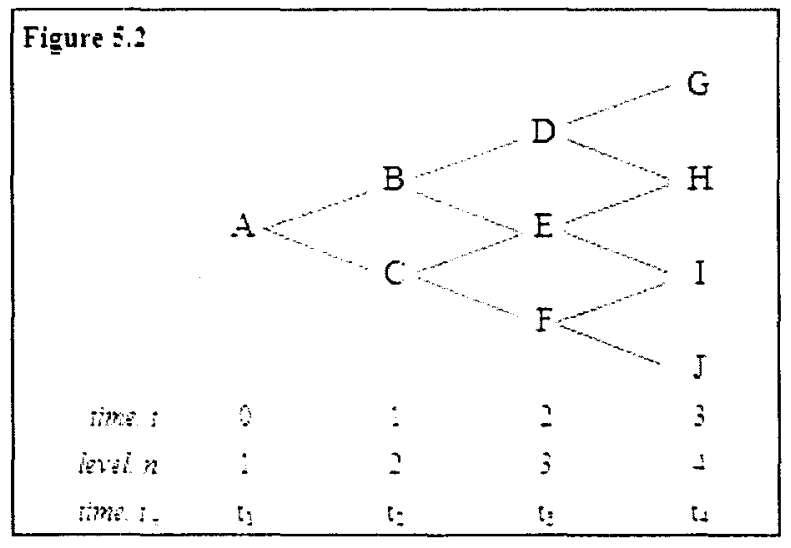

At node $A$ we have the following information: $s_{i}=S_{A}=50, e^{r h}=1.03$, and $\lambda_{A}=1.000$, 
which only leaves the value of $C\left(s_{i}, t_{n+1}\right)=C(50,1)$ to calculate $S_{B}$. But recall that the option prices are either known directly from the market data or can be interpolated from the smile. In this case we are considering an at-the-money call option expiring in one year and having a known volatility of $15 \%$. For simplicity Derman and Kani use the standard CRR model options prices, and we will do the same here in the absence of real market data. Note that the following values can be determined.

$$
\begin{aligned}
& \sigma_{A}=0.15, \\
& u=e^{0.15}=1.1618, \\
& d=e^{-0.15}=0.8607, \\
& p=\frac{1.03-0.8607}{1.1618-0.8607}=0.562
\end{aligned}
$$

Using these values give the results shown in Figure 5.9 below, along with the call option value $C(50,1)=\frac{[0.562(58.09-50)+0.438(0)]}{1.03}=4.42$

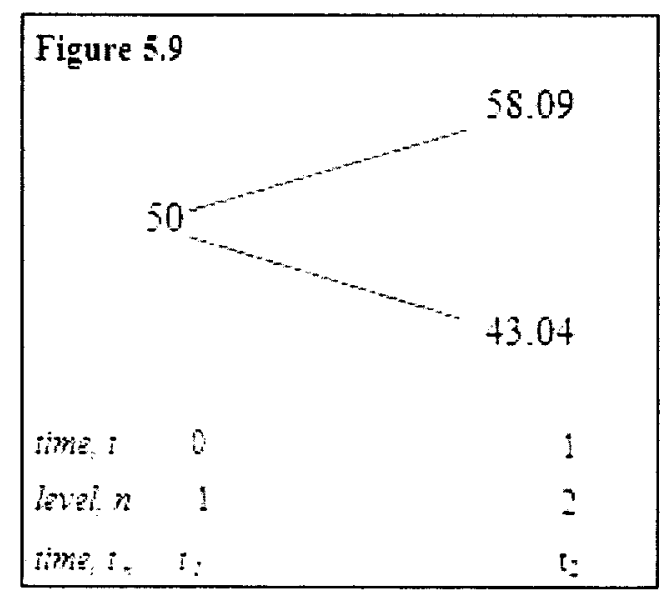

We can now determine the value of $S_{B}$ using Equation 5.12.

$$
\begin{gathered}
S_{i+1}=\frac{s_{i}\left[e^{r \Delta t} C\left(s_{i}, t_{n+1}\right)+\lambda_{i} s_{i}-\Sigma\right]}{\lambda_{i} F_{i}-e^{r \Delta t} C\left(s_{i}, t_{n+1}\right)+\Sigma} \\
S_{B}=\frac{S_{A}\left[1.03 C(50,1)+\lambda_{\mathrm{A}} s_{A}-\Sigma\right]}{\lambda_{\mathrm{A}} 1.03 S_{A}-1.03 C(50,1)+\Sigma}
\end{gathered}
$$


Since there are no nodes above node $B$ at $n=2$, the summation terms are zero and we have.

$$
S_{B}=\frac{50[1.03(4.42)+1.000(50)]}{1.000[1.03(50)]-1.03(4.42)}=58.09
$$

Using the centering condition for even levels, we have the following for $S_{C}$.

$$
S_{C}=\frac{S_{A}^{2}}{S_{B}}=\frac{(50)^{2}}{58.09}=43.04
$$

Now applying Equation 5.7 we can determine the value of $p_{A}^{*}$ as follows.

$$
p_{A}^{*}=\frac{F_{A}-S_{C}}{S_{B}-S_{C}}=\frac{51.50-43.04}{58.09-43.04}=0.562
$$

In general we need to find $S_{i+1}, S_{i}$, and $F_{i}$ in order to calculate $p_{i}^{*}$, but notice at the initial node of the tree it turns out that all values are the same as in the CRR model. For thoroughness we stuck to the model developed by Derman and Kani even for the first period of the tree.

We now move on to $n=3$ and determine the values associated with nodes $D$ and $E$ using the values for node $B$ and Equation 5.11 .

$$
\begin{gathered}
S_{i+1}=\frac{S_{i}\left[e^{r \Delta t} C\left(s_{i}, t_{n+1}\right)-\Sigma\right]-\lambda_{i} s_{i}\left(F_{i}-S_{i}\right)}{\left[e^{r \Delta t} C\left(s_{i}, t_{n+1}\right)-\Sigma\right]-\lambda_{i}\left(F_{i}-S_{i}\right)} \\
S_{D}=\frac{S_{E}[1.03 C(58.09,2)-\Sigma]-\lambda_{B} s_{B}\left(F_{B}-S_{E}\right)}{[1.03 C(58.09,2)-\Sigma]-\lambda_{B}\left(F_{B}-S_{E}\right)}
\end{gathered}
$$

Because of the centering condition where the center of the implied tree is the same as the standard CRR model, we know the implied asset value $S_{E}=50$. And since node $D$ is the highest node for $n=3$, the summation term is zero. We need to calculate the value of the call option $C(58.09,2)$, and again this will be done using the standard CRR model, but with the volatility $\sigma_{B}$ based on the volatility smile. Now we have the following values and can use them to determine the call value as shown in Figure 5.10 below. 


$$
\begin{aligned}
& \sigma_{B}=0.15+0.004\left(\frac{50-58.09}{2}\right)=0.1338, \text { from the smile, } \\
& u=e^{0.1338}=1.1432 \\
& d=e^{-0.1338}=0.8747 \\
& \lambda_{B}=\frac{p_{A}^{*}}{1.03}=\frac{0.562}{1.03}=0.546 \\
& p=\frac{1.03-0.8747}{1.1432-0.8747}=0.578
\end{aligned}
$$

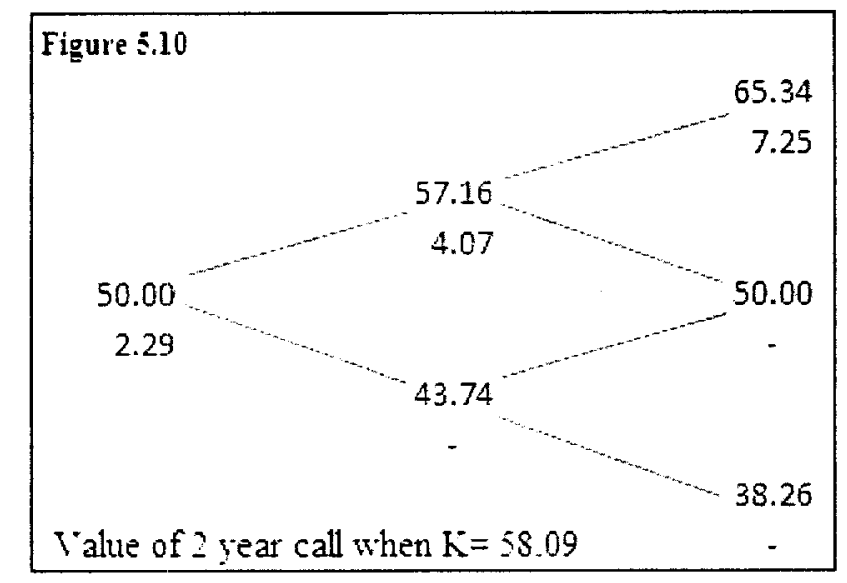

$$
S_{D}=\frac{50[1.03(2.29)]-0.546(58.09)(1.03(58.09)-50)}{1.03(2.29)-0.546(1.03(58.09)-50)}=64.43
$$

Notice that the risk-neutral probability for each node is defined in terms of the implied asset prices of the nodes that it leads to. As a result $p_{i}^{*}$ can only be calculated after the implied asset prices are calculated, and then only for $k-1$ levels in a $k$-period tree as shown later in Figure 5.16. We now have what we need to calculate the risk-neutral probability $p_{B}^{*}$ that generates the implied asset prices of the tree thus far.

$$
p_{B}^{*}=\frac{F_{B}-S_{E}}{S_{D}-S_{E}}=\frac{59.83-50}{64.43-50}=\frac{9.83}{14.43}=0.681
$$

So far we have the following implied asset prices for this model. The process can be continued to calculate the values associated with nodes $G$ and $H$. All values related to this example are shown in the appendix. For now we will move on to the lower half of the 
tree and use the put price methodology to determine the values for node $F$ using Equation 5.13 and the known values for nodes $C$ and $E$ as shown below.

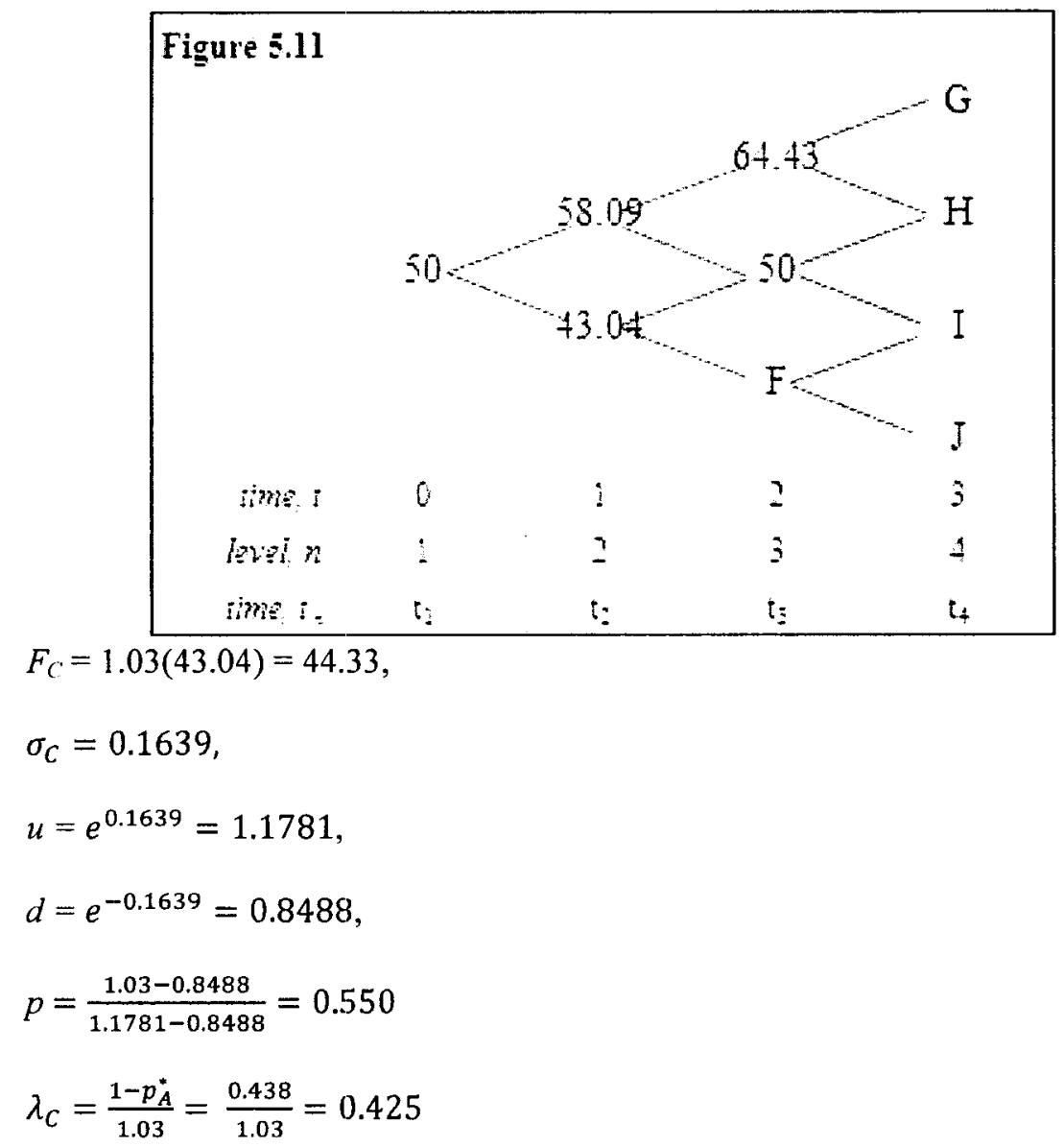

From Equation 5.13 we have the following

$$
\begin{gathered}
S_{i}=\frac{S_{i+1}\left[e^{r \Delta t} P\left(s_{i}, t_{n+1}\right)-\Sigma\right]+\lambda_{i} s_{i}\left(F_{i}-S_{i+1}\right)}{\left[e^{r \Delta t} P\left(s_{i}, t_{n+1}\right)-\Sigma\right]-\lambda_{i}\left(F_{i}-S_{i+1}\right)} \\
S_{F}=\frac{S_{E}[1.03 P(43.04,2)-\Sigma]+\lambda_{C} 43.04(44.33-50)}{[1.03 P(43.04,2)-\Sigma]-\lambda_{C}(44.33-50)}
\end{gathered}
$$

Again the summation terms are zero because there are no nodes below $F$ when $n=3$. We still need the put value $P(43.04,2)$ and determine it to be 1.34 . We can now calculate the implied asset price at node $F$ as well as the risk-neutral probability at node $B$ as follows. 


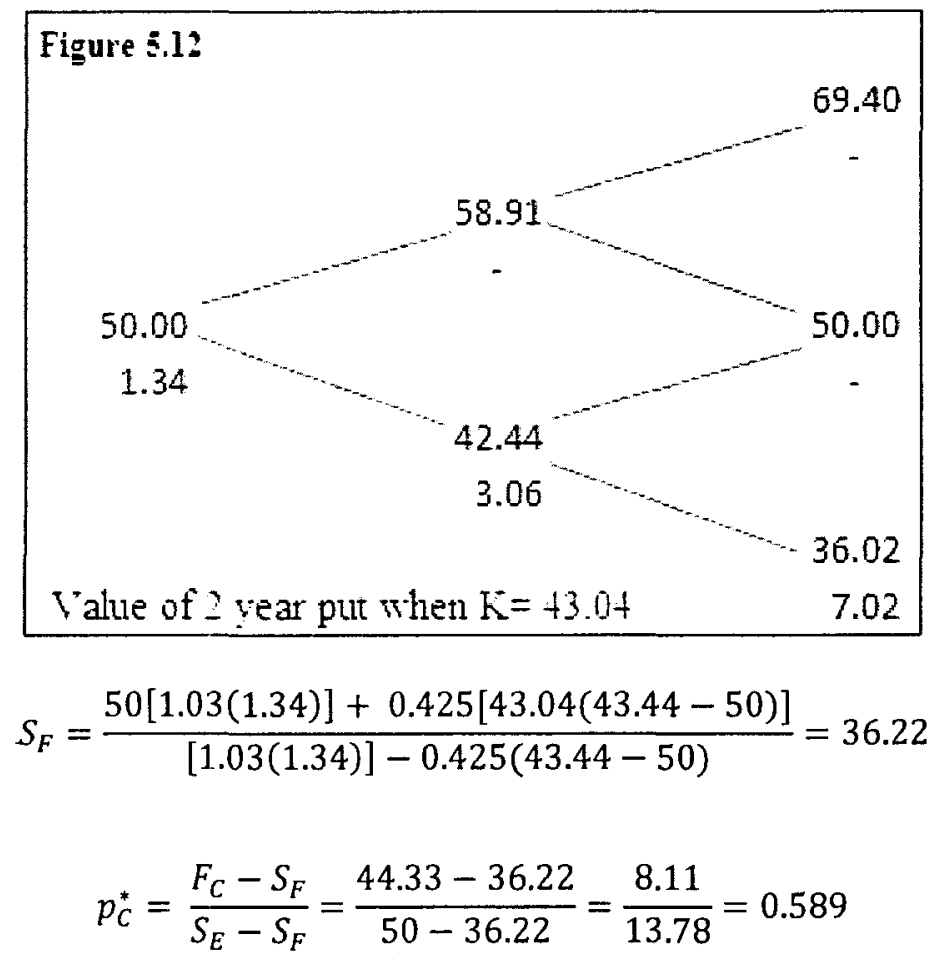

In order to calculate the values for the remaining nodes, namely those for $n=4$, we would start by determining the values of the central nodes $S_{H}$ and $S_{I}$ in a way similar to how the values for $S_{B}$ and $S_{C}$ were determined. In this case the summation term is nonzero since there are additional nodes above and below nodes $H$ and $I$ respectively. The calculations for nodes $H, I$, and the necessary call option are shown below.

$$
\begin{gathered}
S_{\mathrm{H}}=\frac{S_{\mathrm{E}}\left[1.03 C(50,3)+\lambda_{\mathrm{E}} S_{\mathrm{E}}-\Sigma\right]}{\lambda_{\mathrm{E}} 1.03 S_{A}-1.03 C(50,3)+\Sigma} \\
S_{H}=\frac{50[1.03(7.69)+0.412(50)-(0.361)(1.03 \cdot 64.33-50)]}{0.412[1.03(50)]-1.03(7.69)+(0.361)(1.03 \cdot 64.33-50)}=57.64,
\end{gathered}
$$

where $\sum=\lambda_{D}\left(S_{D}-F_{D}\right)=(0.361)(1.03 \cdot 64.33-50)$ represents the sum above node $I$. Using the centering condition for even levels, we have the following for $S_{I}$.

$$
S_{1}=\frac{S_{\mathrm{E}}^{2}}{S_{H}}=\frac{(50)^{2}}{57.64}=43.37
$$




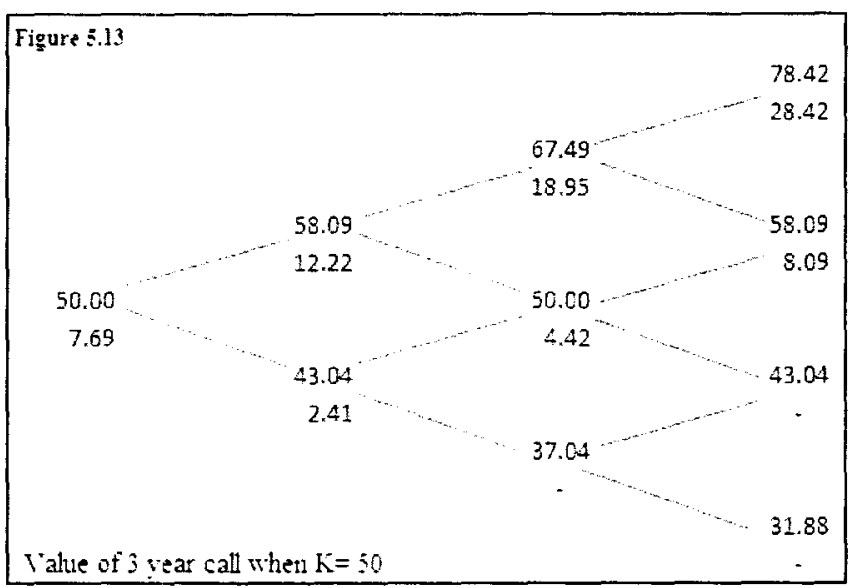

Now applying Equation 5.7 we can determine the value of $p_{E}^{*}$ as follows.

$$
p_{E}^{*}=\frac{F_{E}-S_{\mathrm{I}}}{S_{H}-S_{\mathrm{I}}}=\frac{51.50-43.37}{57.64-43.37}=0.562
$$

Now the values for nodes $G$ and $J$ can be calculated. Below is a demonstration of the calculation for node $J$ only using out values in a way similar to that for node $F$.

$$
S_{J}=\frac{S_{I}[1.03 P(36.22,3)-\Sigma]+\lambda_{F} 36.22(1.03 \cdot 36.22-43.37)}{[1.03 P(36.22,3)-\Sigma]-\lambda_{F}(1.03 \cdot 36.22-43.37)}
$$

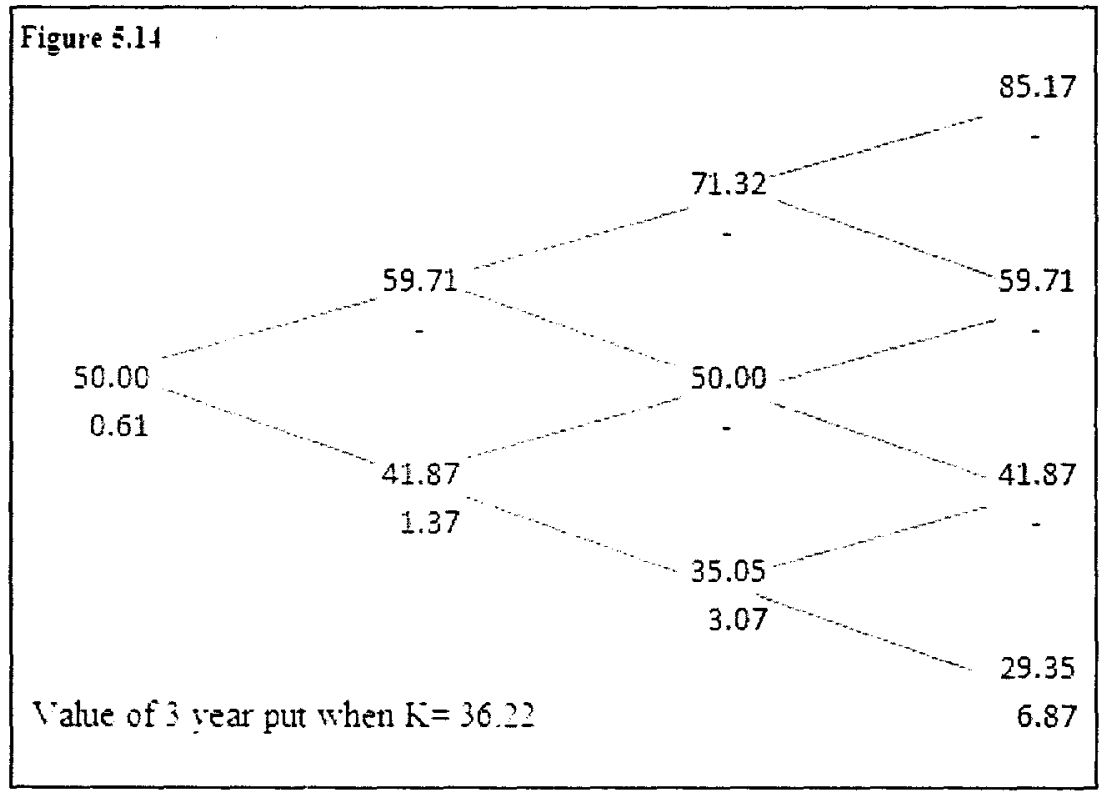

The above figure shows the value of $P(36.22,3)$. Again the summation terms are zero since we are at the bottom of the tree. 


$$
\begin{gathered}
S_{J}=\frac{43.37[1.03(0.61)]+0.170[36.22(1.03 \cdot 36.22-43.37)]}{[1.03(0.61)]-0.170(1.03 \cdot 36.22-43.37)}=25.06 \\
p_{F}^{*}=\frac{F_{F}-S_{J}}{S_{I}-S_{J}}=\frac{37.31-25.06}{43.37-25.06}=\frac{8.11}{13.78}=0.669
\end{gathered}
$$

Figure 5.15 shows the values for the implied asset price tree, risk-neutral probabilities, and Arrow-Debreu prices.

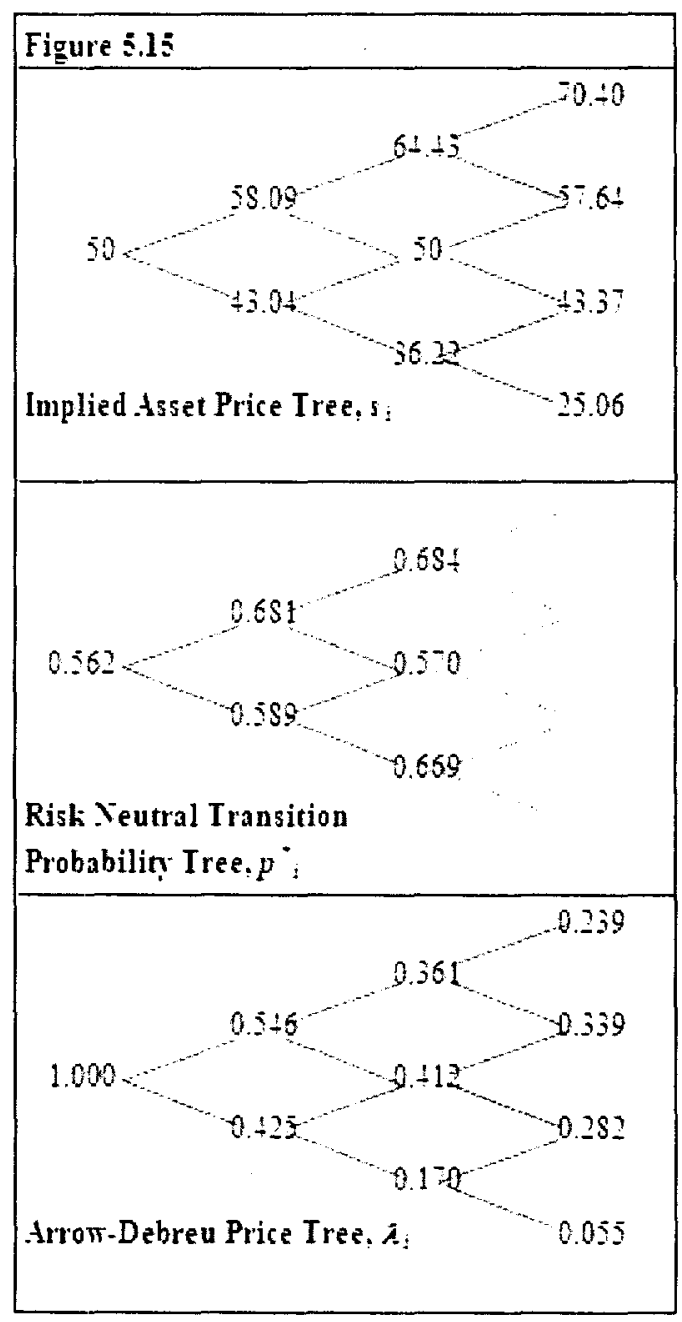

The implied asset price tree that was constructed node-by-node incorporates observed market data, nonconstant implied volatilities, and changing risk-neutral probabilities. The construction of a more sophisticated tree that allows for time periods 
far shorter than a year can be done in exactly the same manner. A practical reason for wanting to know volatility is that option prices in the financial markets are often quoted in terms of volatility. Another reason is to price an option on an asset that is believed to be similar, but for which there is no available market data. Another reason still is to price derivative other than a simple call or put, as the following example demonstrates.

Consider the following example created by the author. Suppose an investor is very optimistic about the potential growth of the asset discussed above and has the opportunity to purchase the following financial instrument on that asset. Let the current asset price be denoted as $S$, where $S=50$. Let $S_{i}$ denote the unknown asset price at $t=3$ at the $i^{t h}$ node from the bottom of the tree and let $g_{i}$ denote the annual growth rate as defined below. The payoff when $t=3, \Pi_{i}$, and the annual growth rate, $g_{i}$, are defined as follows.

$$
\begin{gathered}
\Pi_{i}=\left\{\begin{array}{c}
5\left(S_{3}-S\right), g_{i}>0.05 \\
4\left(S_{3}-S\right), 0<g_{i} \leq 0.05 \\
0, g_{i}=0 \\
3\left(S_{3}-S\right),-0.05 \leq g_{i}<0 \\
4\left(S_{3}-S\right), g_{i}<-0.05
\end{array}\right. \\
S\left(1+g_{i}\right)^{3}=S_{i} \text { or } g_{i}=\left(\frac{S_{i}}{S}\right)^{1 / 3}-1
\end{gathered}
$$

The implied asset price tree, risk-neutral probability tree, and Arrow-Debreu price tree can be used to calculate the arbitrage-free value of this derivative. According to the implied asset price tree, the possible asset prices after three years are $S_{1}=25.06, S_{2}=$ $43.37, S_{3}=57.64$, and $S_{4}=70.40$. These values correspond with the following annual growth rates, $g_{i}$, and payoffs.

$$
g_{1}=\left(\frac{S_{1}}{S}\right)^{1 / 3}-1=\left(\frac{25.06}{50}\right)^{1 / 3}-1=-20.6 \%
$$




$$
\begin{gathered}
\Pi_{1}=4(25.06-50)=-99.76 \\
g_{2}=\left(\frac{S_{2}}{S}\right)^{1 / 3}-1=\left(\frac{43.37}{50}\right)^{1 / 3}-1=-4.6 \% \\
\Pi_{2}=3(43.37-50)=-19.89 \\
g_{3}=\left(\frac{S_{3}}{S}\right)^{1 / 3}-1=\left(\frac{57.64}{50}\right)^{1 / 3}-1=4.9 \% \\
\Pi_{3}=4(57.64-50)=30.56 \\
g_{4}=\left(\frac{S_{4}}{S}\right)^{1 / 3}-1=\left(\frac{70.40}{50}\right)^{1 / 3}-1=12.1 \% \\
\Pi_{4}=5(70.40-50)=102
\end{gathered}
$$

We now use the tree to calculate the value today of this instrument. Refer to Figure 5.16 below.

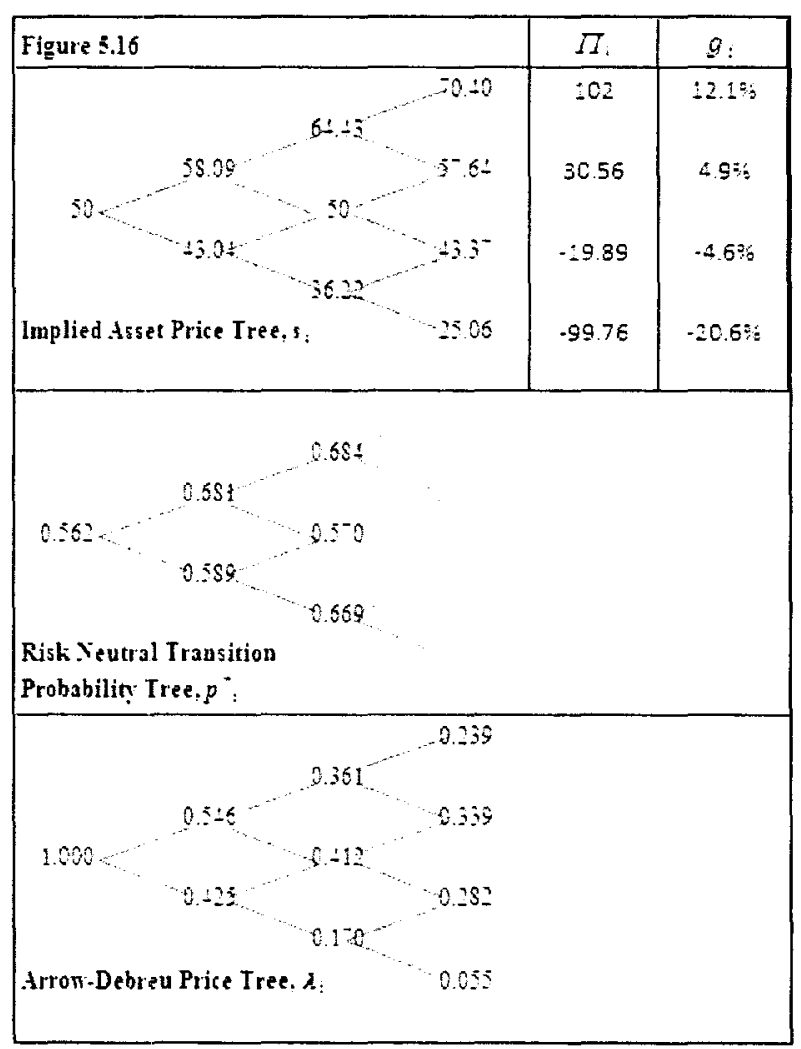


We can use the payoffs at $t=3$, the Arrow-Debreu prices at $n=3$, the risk-neutral transition probabilities for moving from $n=3$ to $n=4$, and the risk free rate $r=2.956 \%$ to determine the price today, $\Pi_{0}$, the derivative as follows.

$$
\begin{aligned}
& \Pi_{0}=\left\{\Pi_{1} \lambda_{F}\left(1-p_{F}^{*}\right)+\Pi_{2}\left[\lambda_{F} p_{F}^{*}+\lambda_{E}\left(1-p_{E}^{*}\right)\right]+\Pi_{3}\left[\lambda_{E} p_{E}^{*}+\lambda_{D}\left(1-p_{D}^{*}\right)\right]+\Pi_{4} \lambda_{D} p_{D}^{*}\right\} / 1.03 \\
& \Pi_{1} \lambda_{F}\left(1-p_{F}^{*}\right)=-99.76(0.170)(0.331)=-5.61 \\
& \Pi_{2}\left[\lambda_{F} p_{F}^{*}+\lambda_{E}\left(1-p_{E}^{*}\right)\right]=-19.89[(0.170)(0.669)+(0.412)(0.430)]=-5.79 \\
& \Pi_{3}\left[\lambda_{E} p_{E}^{*}+\lambda_{D}\left(1-p_{D}^{*}\right)\right]=30.56[(0.412)(0.570)+(0.361)(0.316)]=10.66 \\
& \Pi_{4} \lambda_{D} p_{D}^{*}=102[(0.361)(0.684)]=25.19 \\
& \Pi_{0}=\frac{-5.61-5.79+10.66+25.19}{1.03}=\frac{24.45}{1.03}=23.74
\end{aligned}
$$

In summary, although the popular Black-Scholes formula is widely used and in many cases an accurate representation of financial market activity, it makes some assumptions that are contrary to the observed market data. The assumption of constant volatility across strike prices is one such assumption. However since the Black-Scholes framework is in fact very robust, slight modifications to existing discrete time models allow for the accurate modeling of real market dynamics and more sophisticated derivative pricing. Since the continuous Black-Scholes formula is the limiting case of the standard discrete models as $n \rightarrow \infty$ and $h \rightarrow 0$, the discrete time modifications are good proxies and can easily be adjusted to accommodate less conventional payoff arrangements as demonstrated here. 


\section{REFERENCES}

[1] Arrow, K. and Gerard Debreu, 1954, Existence of General Equilibrium for a Competitive Economy, Econometrica Volume 22, No. 3, 265-290.

[2] Baxter, M.W., and A. J. O. Rennie, 1996 Financial Calculus: An Introduction to Derivative Pricing, Cambridge University Press, New York.

[3] Bjork, T., 1998 Arbitrage Theory in Continuous Time, Oxford University Press, New York.

[4] Black, F. and M. Scholes, 1973 The Pricing of Option and Corporate Liabilities, The Journal of Political Economy, Vol. 81, No. 3, 637-654.

[5] Bookstaber, Richard M., 1981 Option Pricing and Strategies in Investing, AddisonWesley Publishing Company, Inc., Phillipines.

[6] Bru, B., P. Crépel, J. Courtault, Y. Kabanov, A. Le Marchand, and I. Lebon, 2000 Louis Bachelier: On the Centenary of Théorie de la Spéculation, Mathematical Finance, Vol.10, No.3 (July 2000), 341-353.

[7] Çetin, U., R. Jarrow, and P. Protter, 2004 Liquidity Risk and Arbitrage Pricing Theory, Finance and Stochastics 8 311-341.

[8] Çetin, U., R. Jarrow, P. Protter, and M. Warachka, Option Pricing with Liquidity Risk, working paper, Wharton-SMU Research Center of Singapore Management University, http://www.research.smu.edu.sg/or/pdfs/Mitch LiquidityOptions.pdf

[9] Cox, J. C., Ross, S. A., and Rubenstein, M., 1979, Option Pricing: A Simplified Approach, Journal of Financial Economics, 7(3), 229 - 263.

[10] Derman, Emanuel and Kani, Iraj, Riding on the Smile, RISK, 7 (February 1994), $32-$ 39.

[11] Duffie, D., J. Pan, K. Singleton. 2000. Transform Analysis and Option Pricing for Affine Jump-Diffusions. Econometrica 68 1343-1376.

[12] Dupire, Bruno, Pricing with a Smile, RISK, 7 (January 1994), 18-20.

[13] Fama, E.F., L. Fisher, M.C. Jensen, and R. Roll 1969 The Adjustment of Stock Prices to New Information, International Economic Review, Vol. 10. 
[14] Hull, J.C., 2000 Options, Futures, \& Other Derivatives (Fourth Edition), Prentice Hall, Upper Saddle River, New Jersey.

[15] Hull, J.C., 2002 Fundamentals of Futures and Options Markets, Pearson Education, Delhi.

[16] Hull, J., A. White. 1987. The Pricing of Options on Assets with Stochastic Volatilities. Journal of Finance, 42, 281-300.

[17] Jäckel, P., 2002 Monte Carlo Methods in Finance, John Wiley and Sons, New York.

[18] Kendall, M.G., The Analysis of Economic Time-Series-Part I: Prices, Journal of the Royal Statistical Society. Series A (General), Vol. 116, No. 1 (1953), pp. 11-34.

[19] Leland, H.E., 1984 Option Pricing and Replication with Transactions Costs, http://haas.berkeley.edu/finance/WP/rpf144.pdf

[20] Mahler, H. C., 2007, Mahler's Guide to Financial Economics, Georgia State University, J. Mack Robinson College of Business.

[21] McDonald, Robert L., 2006 Derivatives Markets (Second Edition), Pearson Education, Boston, MA

[22] Merton, R.C., 1990 Continuous-Time Finance, Basil Blackwell Inc., Cambridge, MA.

[23] O’Hara, M., 1995 Market Microstructure Theory, Blackwell Publishers, Cambridge, MA.

[24] Poon, Ser-Huang and Granger, Clive W. J., Forecasting Volatility in Financial Markets: A Review, Journal of Economic Literature, Volume XLI, (June 2003), pp. $478-539$.

[25] Protter, P., 2001 A Partial Introduction to Financial Asset Pricing Theory, Stochastic Processes and their Applications, 91, 169-203.

[26] Protter, P. and R. Jarrow, 2004 A Short History of Stochastic Integration and Mathematical Finance: The Early Years, 1880-1970, In The Herman Rubin Festschrift, IMS Lecture Notes 45; 75-91.

[27] Rubenstein, Mark, Implied Binomial Trees, Journal of Finance, July, 1994.

[28] Shreve, S.E., 2004 Stochastic Calculus for Finance I: The Binomial Asset Pricing Model, Springer-Verlag, New York. 


\section{APPENDIX}

\section{Derivation of Equation 5.13}

Recall that the formula for puts is written as

Equation A5.1 $P\left(K, t_{n+1}\right)=e^{-r \Delta t} \sum_{1}^{n}\left\{\lambda_{j}\left(1-p_{j}^{*}\right)+\lambda_{j-1} p_{j-1}^{*}\right\} \max \left(K-S_{j}, 0\right)$

Since the strike price $K$ is set equal to $s_{i}$, the known asset price at $(n, i)$, consider what happens with regard to the transition to the first down node $S_{i}$. The above summation can be simplified by multiplying Equation $\mathrm{A} 5.1$ by $e^{r t}$ then examining the summation term by term beginning with the first in-the-money down move, in other words when $j=i$, then the index of the remaining summation will run from $j=1$ to $j=i-1$ as shown below. For clarity it is shown as the index decreases from the initial node to $j=1$.

\section{Equation A5.2}

$$
\begin{aligned}
& P\left(s_{i}, t_{n+1}\right) e^{r \Delta t}=\lambda_{i}\left(1-p_{i}^{*}\right)\left(s_{i}-S_{i}\right)+\lambda_{i-1} p_{i-1}^{*}\left(s_{i}-S_{i}\right)+\lambda_{i-1}\left(1-p_{i-1}^{*}\right)\left(s_{i}-S_{i-1}\right)+ \\
& \lambda_{i-2} p_{i-2}^{*}\left(s_{i}-S_{i-2}\right)+\lambda_{i-2}\left(1-p_{i-2}^{*}\right)\left(s_{i}-S_{i-2}\right)+\lambda_{i-3}\left(1-p_{i-3}^{*}\right)\left(s_{i}-S_{i-3}\right)+\lambda_{i-3} p_{i-3}^{*}\left(s_{i}-S_{i-3}\right)+ \\
& \ldots+\lambda_{3}\left(1-p_{3}^{*}\right)\left(s_{i}-S_{3}\right)+\lambda_{2} p_{2}^{*}\left(s_{i}-S_{2}\right)+\lambda_{2}\left(1-p_{2}^{*}\right)\left(s_{i}-S_{2}\right)+\lambda_{1} p_{1}^{*}\left(s_{i}-S_{1}\right)+\lambda_{1}\left(1-p_{i}^{*}\right)\left(s_{i}-S_{1}\right)
\end{aligned}
$$

Since there is no path to the lowest node that results from an upward move, the final term in the series is excluded. Notice that the first term in the series above is the contribution of the overall option value resulting from the first nonzero payoff, and the remaining terms are equivalent to Equation A5.1 with a change of index described above. Now consider the sum given by the second and third terms in Equation A5.2, specifically

$$
\lambda_{i-1} p_{i-1}^{*}\left(s_{i}-S_{i}\right)+\lambda_{i-1}\left(1-p_{i-1}^{*}\right)\left(s_{i}-S_{i-1}\right)
$$

By distributing we have 


$$
\lambda_{i-1} p_{i-1}^{*} s_{i}-\lambda_{i-1} p_{i-1}^{*} S_{i}+\lambda_{i-1} s_{i}-\lambda_{i-1} p_{i-1}^{*} s_{i}-\left(1-p_{i-1}^{*}\right) S_{i-1}
$$

By collecting like terms, we have

$$
\lambda_{i-1} s_{i}-\lambda_{i-1}\left[p_{i-1}^{*} S_{i}+\left(1-p_{i-1}^{*}\right) S_{i-1}\right]
$$

Recall the relationship for the forward price $F_{i}$.

Equation A5.3 $F_{i}=p_{i}^{*} S_{i+I}+\left(1-p_{i}^{*}\right) S_{i}$

Solving Equation A5.3 for $p_{i}^{*}$ results in the following.

Equation A5.4 $p_{i}^{*}=\frac{F_{i}-s_{i}}{s_{i+1}-s_{i}}$

Applying Equation A5.3 we have

$\lambda_{i-1} S_{i}-\lambda_{i-1}\left[p_{i-1}^{*} S_{i}+\left(1-p_{i-1}^{*}\right) S_{i-1}\right]=\lambda_{i-1} s_{i}-\lambda_{i-1} F_{i-1}=\lambda_{i-1}\left(s_{i}-F_{i-1}\right)$

Similar results follow for the remaining terms down to to $j=1$. This yields the following overall result.

Equation A5.5 $P\left(s_{i}, t_{n+1}\right) e^{r \Delta t}=\lambda_{1} p_{1}^{*}\left(s_{i}-S_{1}\right)+\sum_{1}^{i-1} \lambda_{j}\left(s_{i}-F_{j}\right)$.

In turn this can be solved for a value $S_{i}$ from the node above it $S_{i+1}$ resulting in Equation 5.13 . 


\section{CURRICULUM VITAE}

NAME: $\quad$ Brian Butler

ADDRESS: $\quad 2200$ Cross Hill Rd

Louisville, KY 40206

DOB: $\quad$ Louisville, KY - October 18, 1969

EDUCATION \&

TRAINING: B.A., Mathematics

Humboldt State University

1989-1993

Exam 1/P, Probability

Society of Actuaries

2002

Exam FM, Financial Mathematics

Society of Actuaries

2006

Validation by Educational Experience, Corporate Finance Society of Actuaries

2007

Validation by Educational Experience, Economics

Society of Actuaries

2007

Validation by Educational Experience, Applied Statistics Society of Actuaries

2007

Minisymposium on Financial Mathematics

Purdue University

April 2005 